\title{
Losses in Efficiency Maps of Electric Vehicles: An Overview
}

\author{
Emad Roshandel ${ }^{1, *}$, Amin Mahmoudi ${ }^{1, *(\mathbb{D}}$, Solmaz Kahourzade ${ }^{2} \mathbb{D}$, Amirmehdi Yazdani ${ }^{3,4}$ \\ and GM Shafiullah ${ }^{3,4}$ (D)
}

check for

updates

Citation: Roshandel, E.;

Mahmoudi, A.; Kahourzade, S.; Yazdani, A.; Shafiullah, G. Losses in Efficiency Maps of Electric Vehicles: An Overview. Energies 2021, 14, 7805. https://doi.org/10.3390/en14227805

Academic Editor: Hugo Morais

Received: 21 October 2021

Accepted: 16 November 2021

Published: 22 November 2021

Publisher's Note: MDPI stays neutral with regard to jurisdictional claims in published maps and institutional affiliations.

Copyright: (c) 2021 by the authors. Licensee MDPI, Basel, Switzerland. This article is an open access article distributed under the terms and conditions of the Creative Commons Attribution (CC BY) license (https:// creativecommons.org/licenses/by/ $4.0 /)$.
1 College of Science and Engineering, Flinders University, Adelaide, SA 5042, Australia

STEM, University of South Australia, Adelaide, SA 5095, Australia; solmaz.kahourzade@unisa.edu.au

3 Discipline of Engineering and Energy, College of Science, Health, Engineering and Education, Murdoch University, Perth, WA 6150, Australia; amirmehdi.yazdani@murdoch.edu.au (A.Y.); GM.Shafiullah@murdoch.edu.au (G.S.)

4 Centre for Water, Energy and Waste, Harry Butler Institute, Murdoch University, Perth, WA 6150, Australia

* Correspondence: emad.roshandel@flinders.edu.au (E.R.); amin.mahmoudi@flinders.edu.au (A.M.)

\begin{abstract}
In some applications such as electric vehicles, electric motors should operate in a wide torque and speed ranges. An efficiency map is the contour plot of the maximum efficiency of an electric machine in torque-speed plane. It is used to provide an overview on the performance of an electric machine when operates in different operating points. The electric machine losses in different torque and speed operating points play a prominent role in the efficiency of the machines. In this paper, an overview about the change of various loss components in torque-speed envelope of the electric machines is rendered to show the role and significance of each loss component in a wide range of torque and speeds. The research gaps and future research subjects based on the conducted review are reported. The role and possibility of the utilization of the computational intelligence-based modeling of the losses in improvement of the loss estimation is discussed.
\end{abstract}

Keywords: copper loss; drive losses; efficiency map; electric machine losses; iron loss; PM loss; transmission system losses

\section{Introduction}

The current motor efficiency standards are limited to the motors for single-speed applications such as fans, pumps, and compressors. NEMA standards [1] classifies the motor efficiencies into four categories named standard efficiency, high efficiency, premium efficiency, and super premium efficiency for 50 and $60 \mathrm{~Hz}$ three-phase and single-phase motors [1-3]. IEC has a similar categorization for determination of the single speed motors efficiency which are known as IE1, IE2, IE3, and IE4 [1]. However, those machines designed for light and heavy electric and hybrid electric vehicles, which should offer a high efficiency over a wide range of torque and speed, are subject to no efficiency regulation [4].

The machine design study for electric and hybrid electric vehicles commonly involves efficiency maps (EMs), which are contour plots of maximum efficiency as a function of torque (or power) versus speed [5-7]. These maps also define the torque/power capability envelope of the machine. The voltage limit (the power converter voltage or the machine insulation tolerance) and current limit (usually set by the machine/inverter thermal limits) must be met by the controllers when the maximum efficiency is calculated. The loss estimation plays an important role in correct estimation of the motor efficiency.

The high-power density of the permanent magnet synchronous motors (PMSM) made them popular in the traction application [8,9]. The high cost of the rare-earth magnet materials of the PMSM motives researchers to improve the efficiency and performance of the induction [10], synchronous reluctance [11], and switched reluctance motors [12-14]. Nowadays, PMSMs are the main part of the propulsion system of the commercialized EVs whereas some models of Tesla electric car such as Tesla Roadster benefit from the low-cost induction machine in its propulsion system [15]. Therefore, the study of the synchronous 
and asynchronous EMs which are the most popular motors in the drivetrain system of the EVs is important to predict the EVs performance over a wide operating range perhaps specific driving cycle.

In traction applications, EMs are widely utilized to estimate the total energy used by the propulsion system of the vehicle over a driving cycle. Figure 1 shows two samples of the driving cycles indicating how the required torque and speed may vary for the electric vehicle (EV) applications. Figure 1c projects the location of the urban dynamometer driving schedule (UDDS) driving cycle points in a sample efficiency map of an induction motor as per the dynamic model of a vehicle considering the motion equations and transmission coefficients.

The electric machine losses vary based on torque and speed operating points. In general, the reason for variation of the loss in different types of electric machines follows the Ohm's law and other physics rules determining the core losses and mechanical losses. However, due to the dependency of the efficiency on the topology of the electric machines the loss variation in different regions is not similar between them. Comparing the EMs of induction motors (IMs), shown in Figure 1c, with those of interior permanent magnet synchronous motors (IPMSMs) shown in Figure 2, it is seen that the IPMSM offers higher efficiency in a wider range of torque-speed. In IMs, the rotor bar losses are high at lower speeds which leads to reduction of the efficiency. The reduction of the copper and core losses at higher speeds result in a high efficiency of IMs in the field weakening region (see Figure 1c). Above a certain speed, the windage and friction losses become dominant, and the efficiency of IMs start to decrease. The efficiency of the permanent magnet (PM) machines around the rated speed (half to two times of the rated speed) is at its highest level (see Figure 2). In these machines, the losses are increased by increment of the speed because of the iron loss and permanent magnet loss increment (see Figure 2a). Additionally, the need for increment of the $d$-axis current in the field weakening region is the main reason of the increment of the copper losses in PM motors.

Identification of the major loss components and analysis of each component helps optimal design of a machine to reduce the losses in a wide-speed range. Figure 3 shows the substantial types of the loss in the drive-train system of EVs. The machine loss splits and their role in in the efficiency of a machine over a wide torque-speed range are discussed in this paper. The review of the considered type of losses reveals which type of the loss has not been properly studied and modelled in literature.

The detailed analysis of the conductive and core losses of the PM and IM machines have been presented in a series of articles [16-18]. The core and ohmic losses in the torquespeed plane have been studied in [19-21]. A comprehensive literature review on the electric motor losses and their dependency on temperature has been conducted in [22]. However, there is no article summarizing the variation of all types of the losses in a wide range of torque and speed.

The content of this survey covers a detailed overview of the sources of the losses in the drivetrain system of an EV. It is a conceptual framework to reconcile the previous works based on their studies and conclusions. The EV's drive-train system consists of electric motor, electric drive, and transmission system. The loss of each part affects the overall efficiency of an EV. In this paper, the details of the variation of each type of loss with different parameters such as voltage, current, speed, and torque are discussed. This overview and detailed loss discussion are a proper reference for the readers to understand the rule of losses in the converter, electric machine, and mechanical transmission system for traction system of EVs. The calculation procedure, measurement method, and role of different loss types as well as possible errors and difficulties of the measurement are explained to understand the behaviour and variation of the losses in a wide-torque speed range that is necessary for an optimum design of the drivetrain system of EVs. The paper finally clarifies the available research gaps and suggests the future works which can be investigated by the researchers in the field. 


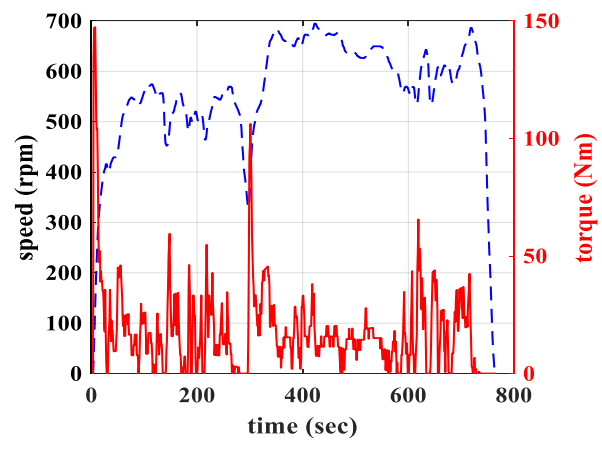

(a)

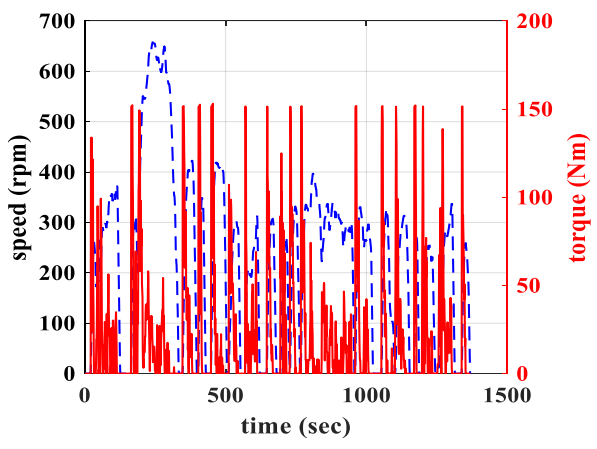

(b)

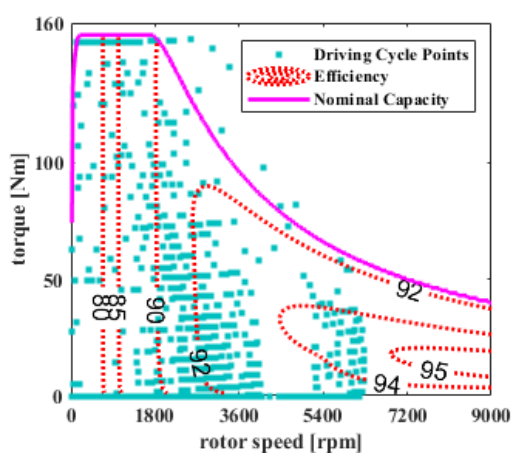

(c)

Figure 1. The torque-speed profiles of two driving cycles introduced for the optimization studies in different literature. The data of this plot has been collected from [23]. (a) Highway Fuel Economy Test (HWFET), (b) Urban Dynamometer Driving Schedule (UDDS), (c) Induction motor efficiency countor and the UDDS driving cycle operating points in the torque-speed envelope.

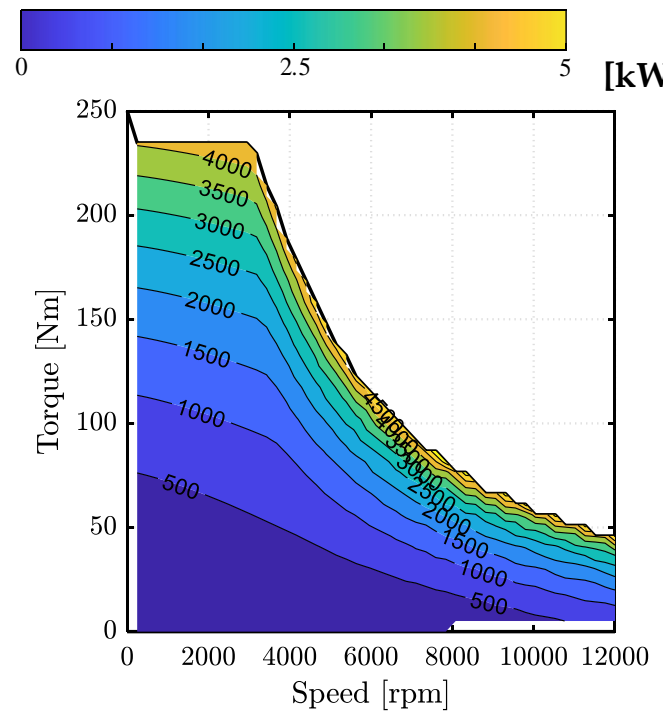

(a)
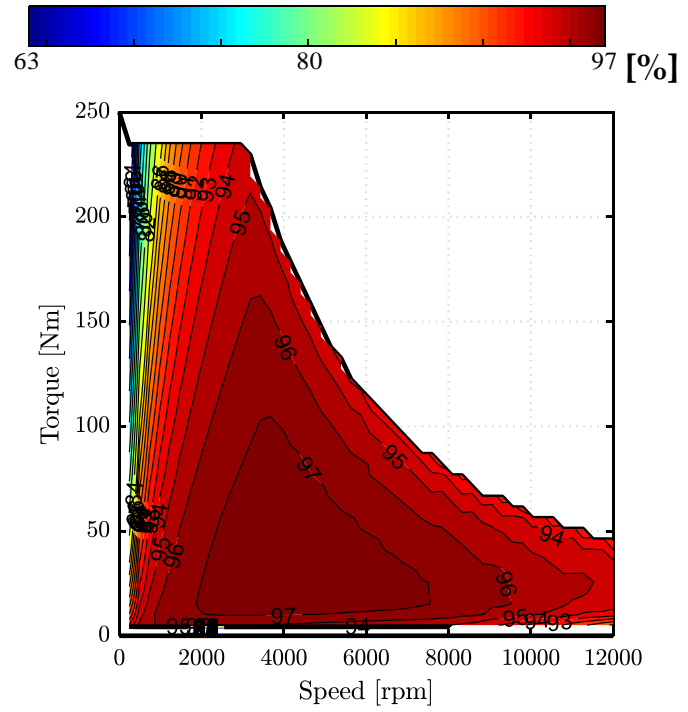

(b)

Figure 2. The loss and efficiency maps of a sample $50 \mathrm{~kW}$ IPMSM subject to operation at its maximum efficiency in each operating point. The studied IPMSM is designed for EV application. The data of this plot has been collected from [20,24]. (a) Total loss map of an IPMSM. (b) Efficiency map of an IPMSM.

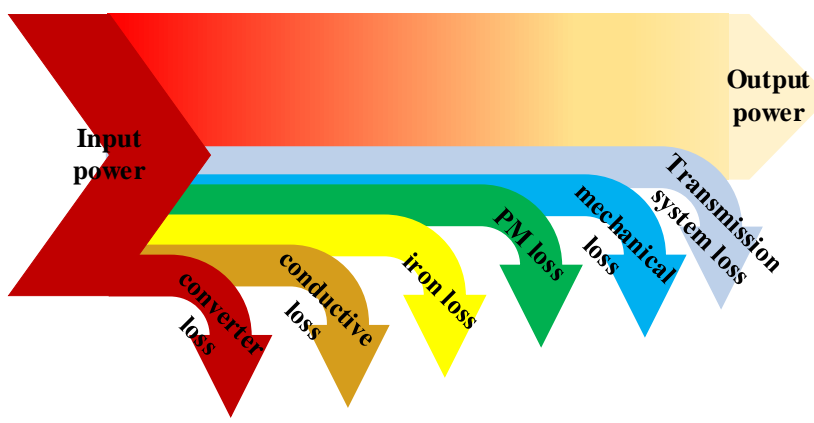

Figure 3. The various loss components of an electric machine used in propulsion system of EVs.

The remainder of this paper is arranged as follows. Section 2 describes the calculation method of each type of loss for each section of the drive-train system of an EV. The variation of the different type of losses in different torques and speeds are described, 
where the important factors affecting each loss portion are determined. The details of the experimental extraction of each loss portion are described in the third section of this document. Finally, research gaps and opportunities for future works are presented based on the literature review.

\section{Losses in the Propulsion System of EVs}

The amount of power losses determines the efficiency of an electric vehicle. The ohmic losses, iron losses, permanent magnet (in PM motors), and converter losses are the main source of the electrical and magnetic dissipation in traction systems. The mechanical sources of the losses including friction, stray, and windage losses are placed in another category of the power dissipation. The transmission system loss is another source of the loss which is discussed in this section.

As shown in Figure 4, except conductive and core losses, just about $50 \%$ of the literature have investigated the other sources of loss in the drivetrain (i.e., all mechanical and electrical parts) of an EV. The references used to extract the required data of Figure 4 are tabulated in Table 1. In practice, precise measurement devices and power analyzers are used for the extraction of the efficiency maps $[25,26]$. It is obvious that in the experimental measurement all categories of losses are included for the EM extraction. Comparison of the results of the computational methods such as finite-element analysis (FEA) or analytical methods with the experimental shows that the most important sources of the losses belong to the conductive and iron losses [27]. Therefore, most of the finite element-based and analytical models used in the efficiency studies tried to model these two portions of the losses accurately $[28,29]$. In this section, the sources of these type of the losses and the determinative factors which affect the value of each loss are discussed. It explains how the losses play an important role in the prediction of efficiency map.

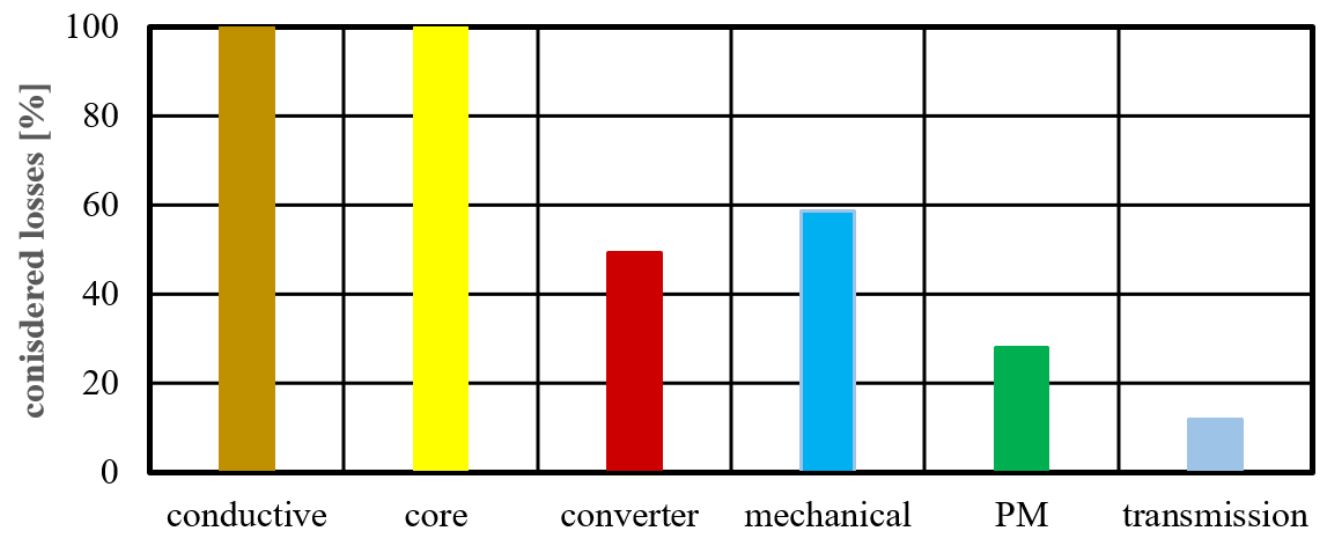

Figure 4. The statistic of documented research focused on the impact of various types of losses on EM of electrical machines during the last three decades (1992 to 2021).

\subsection{Joule (Ohmic) Losses}

Stator winding losses in all types of electric machines and the rotor bar losses in squirrel-cage IMs are defined as the ohmic losses in electric machines [30,31]. The ohmic loss is proportional to the square of current flowing in the conductor $\left(p=R I^{2}\right)$. Furthermore, the skin effect which is the tendency of forcing the alternative current towards the surface of the conductive material significantly affected by the frequency rise, and the conductor temperature increase the amount of conduction losses. In electric motors, winding current has a directly proportional to the produced torque and the speed of the shaft has a direct relationship with the supply frequency. Thus, the ohmic loss varies by both the torque and speed. Figure 5a,b illustrating the current map and ohmic loss map of a $50 \mathrm{~kW}$ IPMSM motor over a driving cycle, demonstrate how the ohmic losses vary with the current amplitude. Such variations are linked with simultaneous changes in torque and speed. To illustrate the difference of the rotor bar and stator winding, Figure $5 c, d$ are presented. As 
expected, the effect of the increment of the current level increases the rotor bar and stator winding losses of the induction machines.

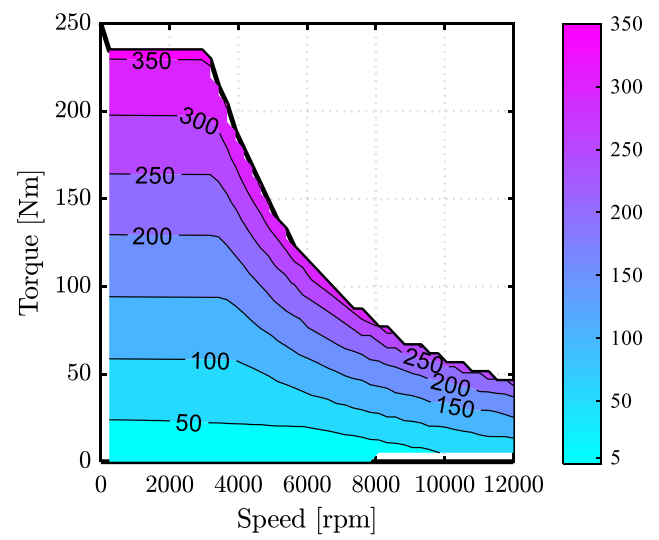

(a)

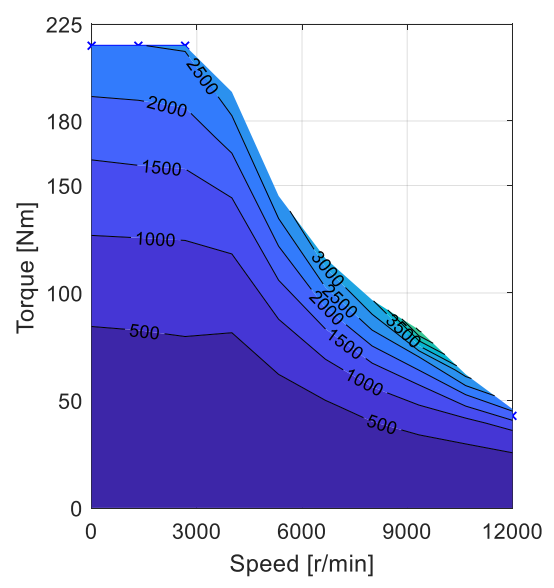

(c)

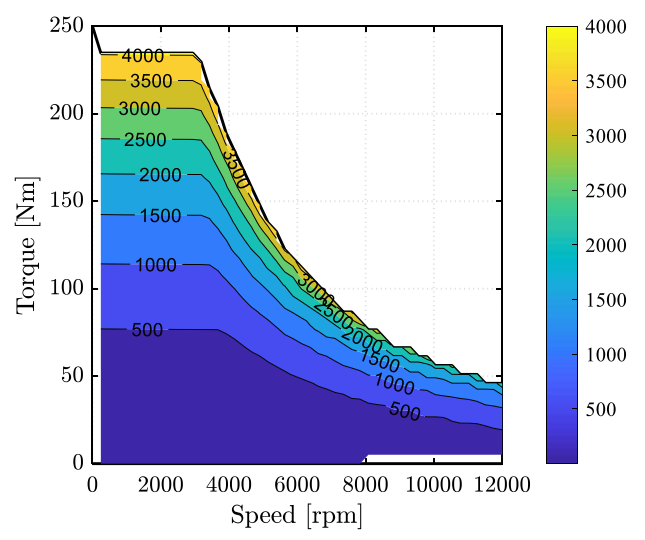

(b)

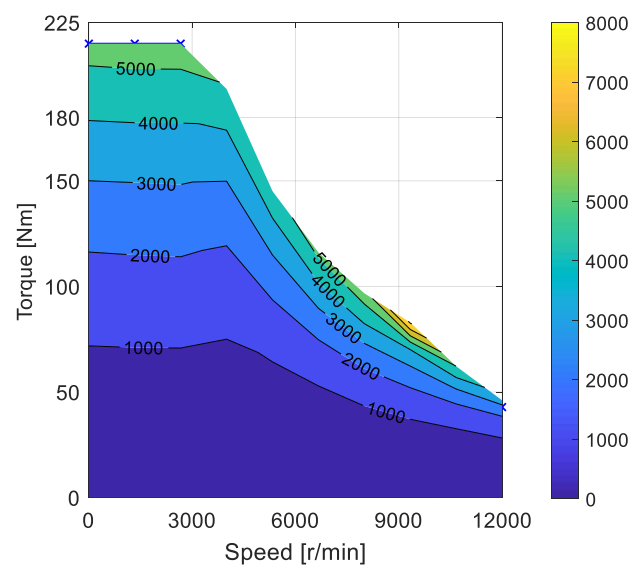

(d)

Figure 5. Current and ohmic loss maps of a $50 \mathrm{~kW}$ IPMSM for operation over a wide torque speed range $[20,24]$ and the contour plot of ohmic losses of a $60 \mathrm{~kW}$ induction machine (rotor bar and stator ohmic loss) [21]. These plots have been provided based on the collected data from [20,21,24]. (a) current map in the torque speed plane. (b) ohmic loss map in the torque speed plane. (c) IM rotor bar loss. (d) IM stator loss.

Researchers in [21], show that the copper losses have different relationships with the torque and speed in both constant torque and constant power regions. The finding indicated the copper losses can be represented as a loss function $\left(T^{m} \omega^{n}\right)$ where $m$ and $n$ determines the share of the torque and speed in copper loss of the machine. Table 2 summarizes the copper loss dependency on the torque and speed of IMs, surface-mounted PM (SPM), and interior-PM (IPM) machines. IMs and IMr point out the stator and rotor ohmic losses of the induction machines in Table 2. It must be highlighted that the powers of speed and torque give an acceptable estimation of the ohmic losses but not an exact value. Some literature $[19,20,32]$ have sought more to improve the accuracy of the loss function. The presented results in these papers are not much accurate based on authors explanations. So, more investigations are required to improve the accuracy of loss function. Nevertheless, Table 2 can be used to approximately understand the relationship of the ohmic losses with the torque and speed in some extent.

In the electric equivalent circuit and 2D FEA models, the winding losses are modeled using the resistance of the stator in the electric equivalent circuit (EEC) or the excitation resistance in 2D FEA [33]. Analytical, empirical equations, and experimental measurement using the $\mathrm{DC}$ and $\mathrm{AC}$ tests are the conventional ways of the calculation of resistance. 3D 
FEA can calculate the resistive losses directly using the integration of the current density over winding volume.

In the analytical and FEA models, the effect of the temperature is investigated by determining a constant value of resistance at higher temperatures. Some commercial software such as Ansys allows to link the electromagnetics analysis with the thermal transient analysis to calculate the temperature variation effect in parallel with the operating condition of the machine [34]. However, such process is computationally expensive and is not useful for prediction of the efficiency map. The analytical models can estimate the skin effect using the analytical equations and curve-fitting techniques [35]. FEA analysis enables considering the skin effect more precisely in higher frequencies [34]. However, it complicates the simulation and consequently increases the simulation time. Usually, the effect of the skin effect is separately analyzed in FEA in different current levels and windings bundles. The calculated results are curve-fitted to correct the calculated losses during a postprocessing process. Considering the required accuracy, it is suggested to derive a proper model which investigates the skin effect and temperature effect in predicting the ohmic losses. Curve fitting is the simplest way of provision of such a model.

Table 1. The type of losses investigated for EM calculation during the last three decades (1992 to 2021).

\begin{tabular}{ccccccccc}
\hline $\begin{array}{c}\text { Reference } \\
\text { Number }\end{array}$ & $\begin{array}{c}\text { Copper } \\
\text { Loss }\end{array}$ & $\begin{array}{c}\text { Core } \\
\text { Loss }\end{array}$ & $\begin{array}{c}\text { Friction } \\
\text { Loss }\end{array}$ & $\begin{array}{c}\text { Windage } \\
\text { Loss }\end{array}$ & $\begin{array}{c}\text { Stray } \\
\text { Stress }\end{array}$ & $\begin{array}{c}\text { Converter } \\
\text { Loss }\end{array}$ & $\begin{array}{c}\text { PM } \\
\text { Loss }\end{array}$ & $\begin{array}{c}\text { Transmission } \\
\text { System Loss }\end{array}$ \\
\hline$[19,20,28,29,36-47]$ & $\checkmark$ & $\checkmark$ & $\checkmark$ & $\checkmark$ & $\checkmark$ & $\times$ & $\times$ \\
\hline$[21,35,48-76]$ & $\checkmark$ & $\checkmark$ & $\times$ & $\times$ & $\times$ & $\times$ & $\times$ \\
\hline$[25-27,30,77-87]$ & $\checkmark$ & $\checkmark$ & $\checkmark$ & $\checkmark$ & $\checkmark$ & $\checkmark$ & $\checkmark$ & $\times$ \\
\hline$[88-96]$ & $\checkmark$ & $\checkmark$ & $\checkmark$ & $\checkmark$ & $\checkmark$ & $\checkmark$ & $\checkmark$ & $\times$ \\
\hline
\end{tabular}

Table 2. The dependency of the machine ohmic losses on the torque and speed of the machine rendering an approximation of the loss in different operating points for each type of the machine [21].

\begin{tabular}{cccccc}
\hline & \multicolumn{2}{c}{ Constant Power Region } & \multicolumn{2}{c}{ Constant Torque Region } \\
\hline $\mathrm{T}^{2}$ & $\mathrm{IM}_{\mathrm{s}}, \mathrm{IPM}, \mathrm{SPM}$ & $\mathrm{IM}_{\mathrm{r}}$ & $\mathrm{IPM}, \mathrm{SPM}$ & $\mathrm{IM}_{\mathrm{s}}, \mathrm{IM}_{\mathrm{r}}$ \\
\hline $\mathrm{T}$ & $\mathrm{IM}_{\mathrm{s}} \mathrm{IPM}$ & & $\mathrm{IM}_{\mathrm{r}}$ & $\mathrm{IM}_{\mathrm{s}}$ \\
\hline 1 & $\mathrm{IM}_{\mathrm{s}}$ & & $\mathrm{IPM}, \mathrm{SPM}$ & & \\
\hline 1 & $\omega$ & 1 & $\omega$ & $\omega^{2}$ \\
\hline
\end{tabular}

\subsection{Core Losses}

Core losses are another determinative factor in the efficiency calculations. Steinmetz equation is the well-known method of the calculation of the core losses. Steinmetz showed that the core losses are varied with the frequency and flux density of the machine [97]. Later in $[98,99]$, the generalized and improved generalized Steinmetz equation were introduced to take the hysteresis effect into account. These methods were new but did not consider the effect of the variation of the Steinmetz coefficients with the frequency. Thus, the core loss estimation using these techniques is not accurate when the supply voltage includes a wide range of harmonics. A loss separation model based on the Steinmetz equation was introduced and improved in [100-104]. The results of the research on the iron loss separation modelling introduced a loss model with three major components summarized in (1). The iron losses consist of the hysteresis $\left(P_{h}\right)$, eddy current $\left(P_{e d}\right)$, and excess losses $\left(P_{e x}\right)$ are calculated by the Stienmetz equations presented in (1). 


$$
\left\{\begin{array}{c}
P_{h}=k_{h} f B^{2} V \\
P_{e d}=k_{e d} f^{2} B^{2} V \\
P_{e x}=k_{e x} f^{1.5} B^{1.5} V
\end{array}\right.
$$

where $k_{h}, k_{e d}$, and $k_{e x}$ are the Steinmetz constants of hysteresis, eddy current, and excess losses which depend on the lamination material used in the structure of the rotor and stator. $f, B$, and $V$ are the operating frequency, flux density, and iron volume, respectively. According to the Stienmetz equations, core losses are increased by the increment of the frequency and flux density [64,105].

There are several papers discussing the dependency of the Steinmetz coefficients on the operating temperature of the electric machine [106-108]. According to the presented results in [106], electric machine core losses are reduced by temperature increase. It is logical because of the reduction of the iron electric conductivity by increment of the temperature and consequently reduction of the eddy current losses in the iron parts.

The loss separation approach offers an acceptable accuracy for prediction of iron loss although it ignores the effect of the history of flux density waveform. Ignoring the history of the flux density waveform means that the instantaneous flux density and its rate of variation are the only responsible factors in determining the core loss. In the inverter driven systems where the high order harmonics distort the flux density a minor hysteresis loops need to be taken into account [109]. Disregarding the minor hysteresis loop is another source of the in accuracy in loss separation technique. To address this issue in the loss separation models, Preisach [110] and Jiles/Atherton [111] models, which are called hysteresis models, were introduced. The hysteresis loss density in the Presiach model is obtained using the integration of the multiplication of flux intensity by the rate of variation of flux density over a period. These models were also improved in several research to enhance the accuracy of the iron loss prediction [112-114]. These models offer higher accuracy compared to the loss separation model but require more computational and mathematical efforts which complicates the iron loss modelling.

Most of the commercial finite element software such as Ansys Electromagnetics [34] and Motor-Cad [115] employ (1) to predict the core losses. To improve the accuracy of the core loss prediction, JMAG [116] uses a frequency separation approach in the post processing [117]. The frequency separation allows to investigate the minor loop hysteresis losses. This software uses time series data of magnetic flux density to consider the size of the hysteresis and predict the hysteresis losses [118].

The loss separation technique for estimation of the core losses is not limited to the FEA based software. Some analytical models which can estimate the flux density in the iron parts have employed in (1) to predict the core loss [119-121]. The estimation of the flux density based on the sizing equation and magnetic equivalent circuit of the electrical machines allows to find the core loss by (1) [122-124].

The no-load test at the induction motor and combination of the open circuit and short circuit tests in the synchronous motor are the common experimental ways of the measurement of core losses [48]. The core loss is usually modeled with a resistance in the electric equivalent circuit of the electric motors. So, authors estimate the core losses for a certain frequency and voltage level to find a proper value of the core resistance in EEC and find the core loss by solving the circuit in different supply voltages and frequencies [23].

In the variable speed applications such as EVs, electric motors are driven by inverters. The core loss value is changed by the variation of the carrier frequency because of the appearance of the high order harmonics in the output pulses of the power converter. According to the conducted study in [18], the core losses of an inverter driven PM motor is increased by $45 \%$ compared to a sinusoidal supply voltage.

The dependency of the core losses on various factors complicates the accurate prediction of the core losses over a driving cycle [125]. The introduction of a loss function in [21] was a fast and fairly accurate approach to predict the electric machine core losses in 
the torque speed plane. Table 3 summarizes the core loss variation in IM, SPM, and IPM motors in different operating regions.

Table 3. The dependency of the machine core loss on the torque and speed of the machine rendering an approximation of the loss in different operating points for each type of the machine [21].

\begin{tabular}{|c|c|c|c|c|c|c|}
\hline \multirow[b]{2}{*}{$\mathrm{T}^{2}$} & \multicolumn{3}{|c|}{ Constant Power Region } & \multicolumn{3}{|c|}{ Constant Torque Region } \\
\hline & & IPM & IM, IPM & & & \\
\hline $\mathrm{T}$ & & & $\mathrm{IM}$ & IM & & \\
\hline 1 & & IPM, SPM & IM, IPM, SPM & IM, IPM, SPM & & IPM \\
\hline & 1 & $\omega$ & $\omega^{2}$ & 1 & $\omega$ & $\omega^{2}$ \\
\hline
\end{tabular}

The dependency of the core loss on the frequency and supply voltage of the machine affects this value over a driving cycle. Figure 6 illustrates the voltage map and core loss maps of a $50 \mathrm{~kW}$ IPMSM and $45 \mathrm{~kW}$ SPMSM. As expected in the field weakening region where the machine works in higher speeds and the voltage level is at its maximum level, the core losses are significant [30]. The comparison of the core loss maps of these machines shows that SPMSM has a much larger core losses at higher speeds. For this reason, the IPMSM is popular in EV applications.

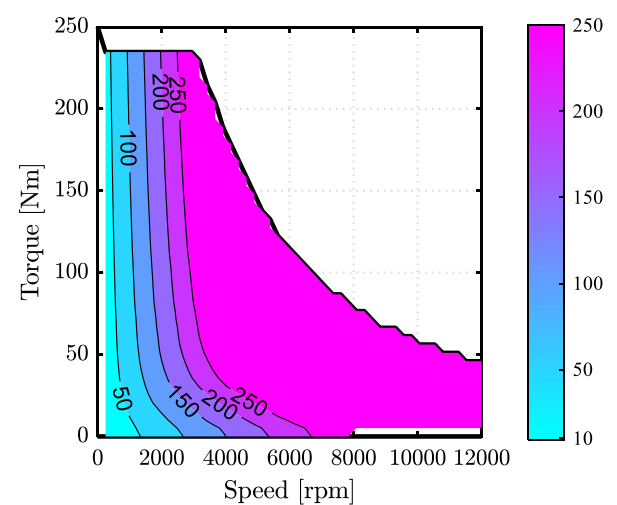

(a)

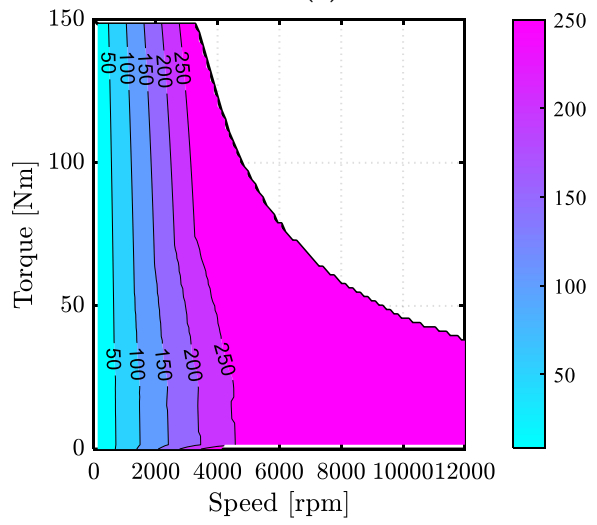

(c)

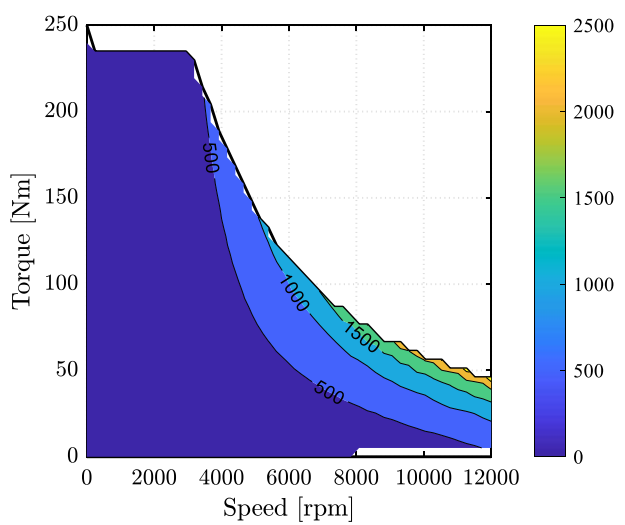

(b)

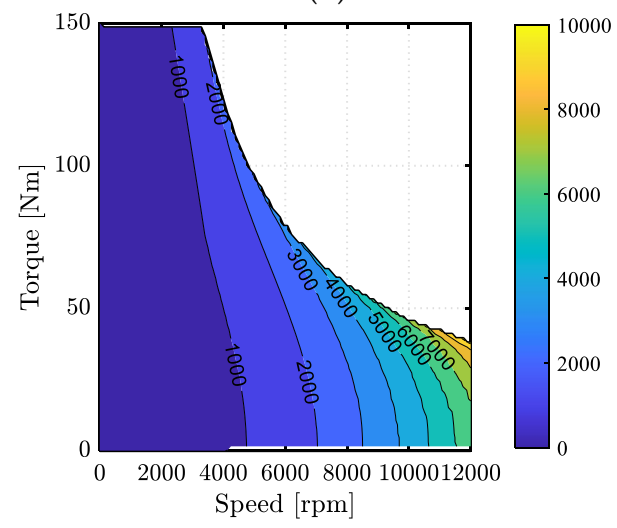

(d)

Figure 6. Voltage and core loss maps of a $50 \mathrm{~kW}$ IPMSM and $45 \mathrm{~kW}$ SPMSM for operation over a wide torque speed range. These plots have been provided based on the collected data from [20,24]. (a) voltage map in the torque speed plane for the IPMSM. (b) core loss map in the torque speed plane for the IPMSM. (c) voltage map in the torque speed plane for the SPMSM. (d) core loss map in the torque speed plane for the SPMSM. 


\subsection{Converter Loss}

The power converters (electric drive system) losses are other sources of the electrical losses considered in the efficiency studies [82]. A switch loss is composed of the conductive loss $\left(P_{s w, r m s}\right)$, switching at turn on and off losses $\left(P_{s w, o n}\right.$ and $\left.P_{s w, o f f}\right)$, output capacitance loss $\left(P_{s w, o s s}\right)$, and gate loss $\left(P_{s w, g a t e}\right)$. As shown in (2), the conductive loss depends on the rms current $\left(I_{r m s}\right)$ where the switch conducting resistance $\left(R_{s w}\right)$ is assumed constant. The rising time, falling time, energy stored in the output capacitance, and gate charge of a switch shown by $t_{o n}, t_{\text {off }}, E_{o s s}$, and $Q_{g}$ are constants. According to (3) to (6), the switching losses depend on the switching frequency $\left(f_{s w}\right)$, DC-link voltage $\left(V_{D C}\right)$, and $I_{r m s}$.

$$
\begin{gathered}
P_{s w, r m s}=R_{s w} \cdot I_{r m s}^{2} \\
P_{s w, o n}=0.5 \cdot I_{r m s} \cdot V_{D C \_l i n k} \cdot t_{o n} \cdot f_{s w} \\
P_{s w, o f f}=0.5 \cdot I_{r m s} \cdot V_{D C \_l i n k} \cdot t_{o f f} \cdot f_{s w} \\
P_{s w, o s s}=E_{o s s} \cdot f_{s w} \\
P_{s w, g a t e}=V_{g} \cdot Q_{g} \cdot f_{s w}
\end{gathered}
$$

The voltage is at its maximum level in the constant power region (see Figure 6a). Thus, $P_{s w, o n}, P_{s w, o f f}, P_{s w, o s s}$, and $P_{s w, g a t e}$ are increased by increment of the shaft speed [126]. The temperature of the switches in power converter is another important factor which affects the converter switching loss. The conduction losses $\left(P_{s w, r m s}\right)$ are increased by the temperature rise due to higher value of the switch series resistance $\left(R_{s w}\right)$ [127]. Literature shows that the influence of the temperature variation on the conduction losses is much smaller than the switching losses $\left(P_{s w, o n}\right.$ and $\left.P_{s w, o f f}\right)$ [128]. It was shown that under half of the rated current, the switching losses are increased up to $20 \%$ when the temperature varies from $25^{\circ} \mathrm{C}$ to $200{ }^{\circ} \mathrm{C}$ [128]. This change in larger currents is bigger. For instance, at rated current, the switching losses are increased from $60 \%$ to $140 \%$ of the rated switching losses when the temperature changes from $25^{\circ} \mathrm{C}$ to $200^{\circ} \mathrm{C}$ during the operation [128]. This significant variation of the losses necessitates a proper cooling system for prompt operation of the power converters at various ambient temperatures.

Existing methods usually ignore the converter losses in estimation of the efficiency maps. However, literature shows that the semiconductor losses in the constant torque and field weakening regions are approximately at least one-third of the total losses [89]. The results presented in [89] shows the semiconductor loss in field weakening region is much larger than the conductive losses and at least half of the core losses. Figure 7 [89] compares the value of the drive (converter) losses with the conductive and core losses in different driving cycles. It shows the converters losses are a large portion of the total losses and hence needs to be considered for an exact efficiency map. 


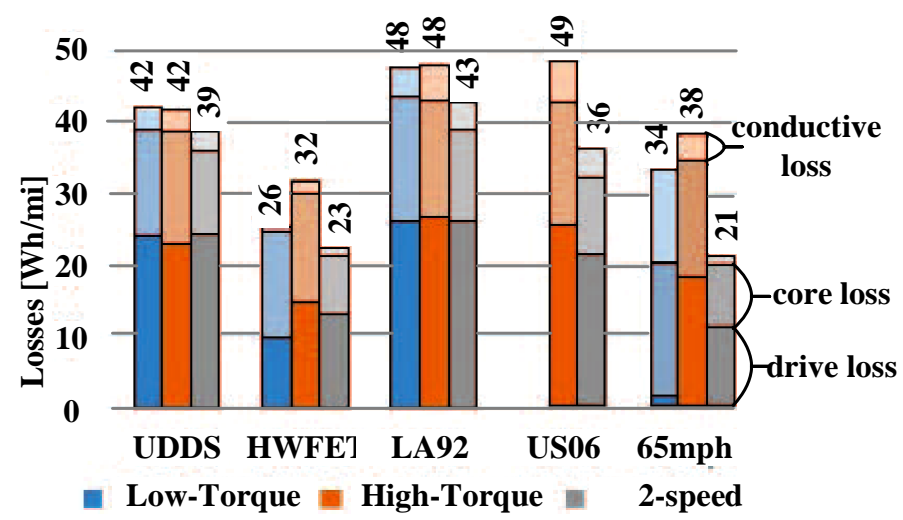

Figure 7. The measured copper, core and drive (converter) losses per mile for three different machine/gearbox combinations in 4 drive cycles and constant speed of $65 \mathrm{mph}$ operation reported in [89].

\subsection{Permanent Magnet Losses}

The conductivity of the PM materials allows the eddy current to flow with in the magnet [129]. The induced current in the PMs is high when the magnet volume is large. Although in the large electric motors the segmented sintered rare-earth magnets are used to reduce the eddy-current, the PM loss is still large. According to the results presented in [52], the PM eddy current loss increases by 50 times above $5000 \mathrm{rpm}$. Figure 8 visualizes the effect of the variation of the rotor speed on PM loss [130]. Thus, it is important to estimate the PM losses when the machine efficiency is reported over a wide speed range.

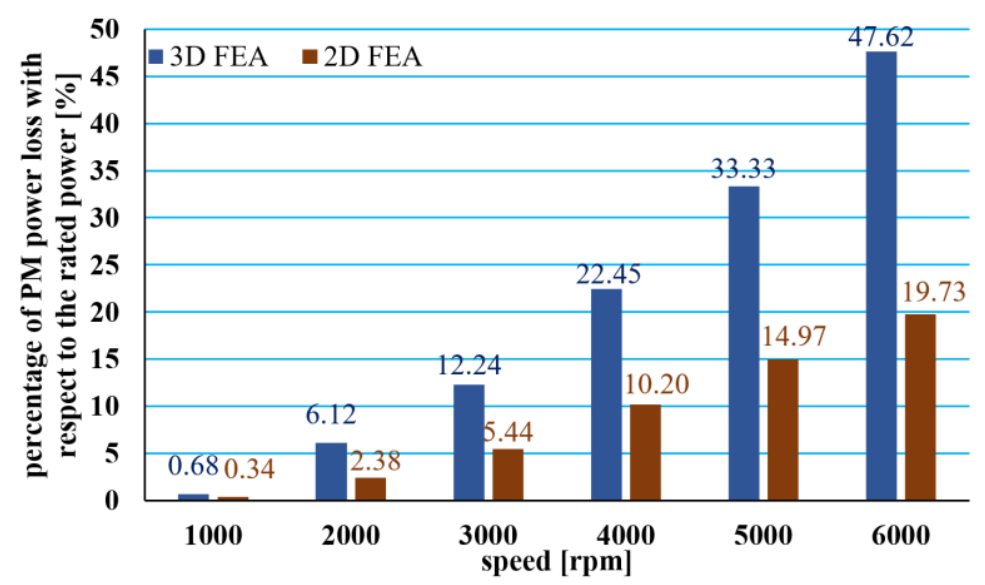

Figure 8. Non-segmented PM power loss in different operating speeds and comparison of the accuracy of the 2D and 3D FEA results for a $14.7 \mathrm{~kW} 4000 \mathrm{rpm} 16$ pole machine. The data to plot this figure was collected from [130].

The time and frequency domain FEA are the widely used approaches for the calculation of PM losses. The PM loss calculation by 2D FEA is fairly accurate in radial flux machines [131]. The 3D FEA is necessary for calculation of the PM loss in axial-flux machines [132]. In some specific dimensions and topologies, the 2D FEA cannot predict the PM loss properly. In general, axial-flux machines necessitate 3D FEA if precision is required [133]. Figure 8 shows the difference between the 2D and 3D FEA results for a 16-pole machine [130]. Although the machine is radial flux, there is a large difference between the 2D and 3D FEA results. In addition, when the segmented or skewed magnet structures are utilized in the rotor the 3D FEA is required to find the PM losses as well as the machine performance [134,135]. 
The FEA models are accurate but computationally expensive. Hence, authors have devoted time and energy to estimate the PM loss using the fast analytical models [136]. The available analytical models only considered the armature reaction [137] and slot effects [22] for calculation of the PM loss. In these models, the eddy current loss is the only investigated portion of the PM loss and the hysteresis PM loss is ignored [22]. It was shown that the hysteresis losses are approximately two times of the eddy current losses in PMs [138]. Therefore, consideration of the PM loss without investigation of hysteresis loss is not accurate. The loss mapping technique is a type of the analytical modelling to the PM losses $[129,130,139]$. It is fast, but limited to a type of the magnet, shape of the rotor, and shape of the stator. For this reason, the PM loss mapping and the developed loss functions are limited to a specific machine and geometry.

\subsection{Mechanical Losses}

In addition to the electrical and magnetic losses mentioned in previous sections, the mechanical losses including windage [140], friction [37] (mechanical losses [64]), and stray losses [74] are other sources of the power dissipation in the efficiency studies of the electrical machines. The friction and windage losses value depend on the mechanical speed, shaft radius, shaft length, and the environment in which machine works in [140]. According to the Mack's equation shown in (7), the mechanical loss which is the summation of the friction and windage losses is related to the cube of the operating speed.

$$
P_{\text {mech }}=\pi C_{f} \rho \Omega^{3} r_{r o t}^{4} L
$$

In this equation, $\rho$ and $C_{f}$ are the fluid density around the rotor and friction coefficient, respectively. The rotor speed and its radius are shown by $\Omega$ and $r_{\text {rot }}$ where $L$ is the rotor axial length. According to the reported findings in [64], the mechanical and stray losses have a direct relationship with the speed of the machine and the output power. The mechanical losses consideration in most of the analytical calculations are ignored because they include a small portion of the total losses. Moreover, the modelling of temperature effect on the efficiency of bearings is not easy and hence often ignored. In [141], the effect of the speed and temperature on the variation of the mechanical losses was studied. According to Figure 9, the effect of the speed is dominant compared to the temperature effect. This figure shows the maximum value of $200 \mathrm{~W}$ mechanical loss for a $14.9 \mathrm{~kW}$ axial-flux PM motor. If the maximum efficiency of this machine is $90 \%$ [141], the mechanical loss is about $12 \%$ of the total losses at high speeds which is not a negligible value in the efficiency calculation.

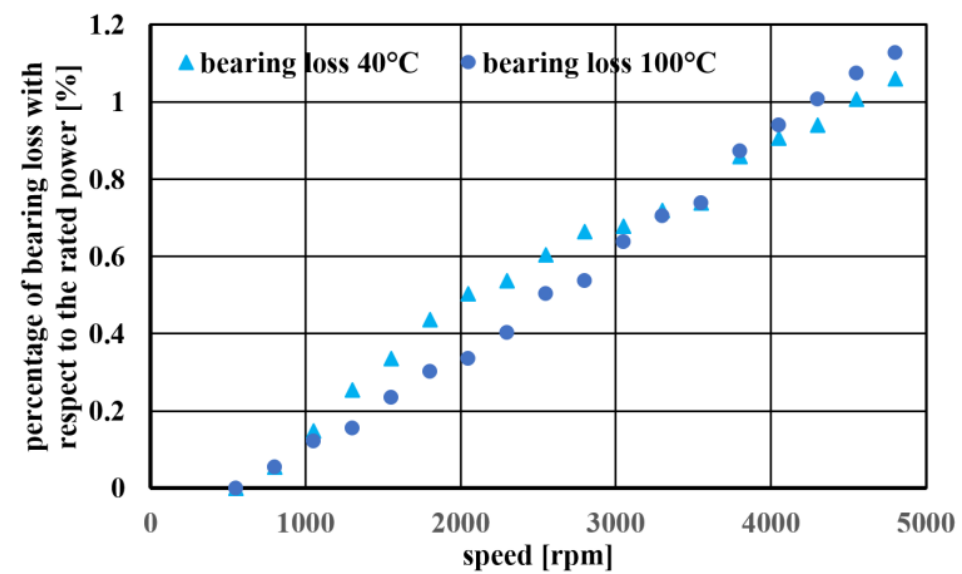

Figure 9. The mechanical loss variation in a $14.9 \mathrm{~kW}$ axial-flux PM motor against speed in two different temperature machines. The data to plot this figure was collected from [141]. 


\subsection{Transmission System (Mechanical Drivetrain) Losses}

Efficiency maps are widely studied in electrical machine design for EVs where the motor must operate in different speeds. Therefore, the analysis of the transmission system losses in different torques and speeds are important to precisely estimate the efficiency maps of an EV.

The in-wheel and in-body are two types of the transmission system used in EVs. Singlestage transmission, multi-stage transmission, and continuously variable transmission (CVT) are the widely used mechanical systems in the drivetrain of EVs [142]. The availability of these transmissions systems is necessary to distribute and deliver the generated power to the wheels of an EV with the in-body drivetrain. Although the transmission can be removed from the in-wheel drivetrain, literature has suggested the utilization of a reduction gear in this system [143] because of the higher efficiency of the electric machines during operation at the field weakening region (e.g., see the efficiency maps in Figures $1 c$ and 2b).

Gearbox, propeller shaft, differential, and drive shaft are the main components of the single and multi-speed transmission systems. The comparison of the single-speed and two-speed transmission systems, shown in Figure 10, demonstrates that they differ in the number of gears. Although increment of the number of gears leads to the increase of the mechanical losses in transmission system, the overall efficiency of the machine in the presence of multi-speed transmission system is higher [144]. This improvement of the efficiency resulted from the operation of the electric machine in the field weakening region where its efficiency is higher. CVT is the widely used transmission system in commercialized EVs such as Honda, Nissan, and Toyota. The efficiency of the CVT is fairly higher than the other types of the transmission system. Moreover, it offers a continues torque where its counterpart (multi-speed transmission system) suffers from the torque interruption during the operation [142].

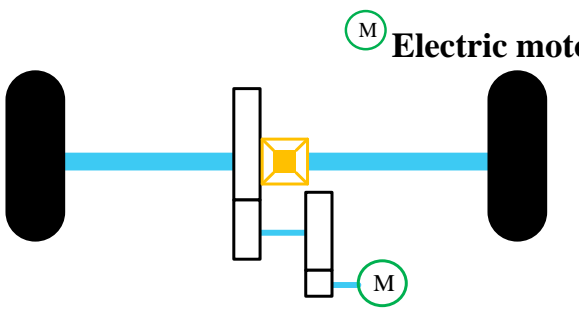

(a)

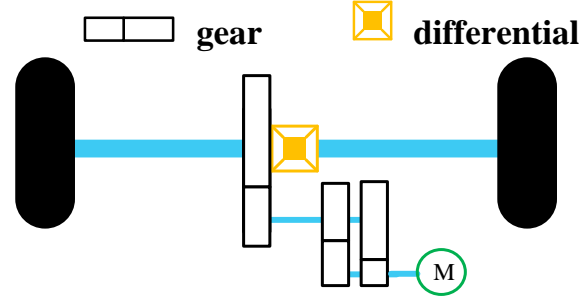

(b)

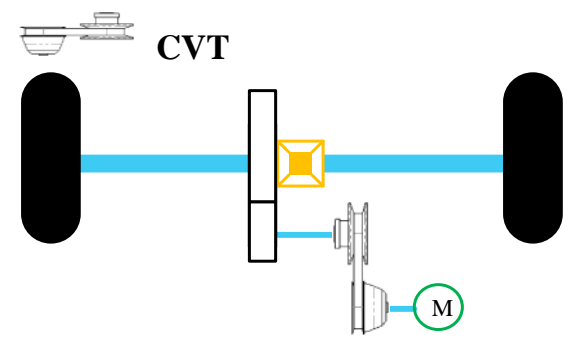

(c)

Figure 10. The graphical illustration of three widely used transmission systems in EVs [142]. (a) single-speed transmission. (b) two-speed transmission. (c) CVT transmission.

\subsubsection{Loss and Efficiency in the Single and Multi-Speed Transmission Systems}

The gear mesh and bearings efficiency are two main factors in determination of the gearbox efficiency [145]. If the $N_{b g}$ and $N_{g m g}$ show the number of the bearings and gear meshes respectively, the efficiency of the gear box is obtained by (8); whereas the bearing and gear mesh efficiency are shown by $\eta_{b r}$ and $\eta_{g m g}$, respectively [146].

$$
\eta_{g b o x}=\eta_{b g}^{N_{b g}} \times \eta_{g m g}^{N_{g m g}}
$$

The torque is transmitted from the gearbox to the axle through the propeller shaft $[147,148]$. The propeller shaft efficiency depends on the number of bearings $\left(N_{b p}\right)$ and universal joints $\left(N_{u p}\right)$ and their efficiency. The total efficiency of the propeller shaft is calculated by (9) where $\eta_{b p}$ and $\eta_{u p}$ are the bearing and universal joints efficiencies in the structure of the propeller, respectively.

$$
\eta_{p s h}=\eta_{b p}^{N_{b p}} \times \eta_{u p}^{N_{u p}}
$$


The differential splits the torque to be applied to the right and left wheels. So, it is considered as the last gear reduction part of the in-body transmission system [149]. The efficiency of the differential, written in (10), depends on its gear mesh efficiency $\left(\eta_{g m d}\right)$ and bearing efficiency $\left(\eta_{b d}\right)$. In (10), $N_{b d}$ shows the number of differential bearings.

$$
\eta_{\text {diff }}=\eta_{b d}^{N_{b d}} \times \eta_{g m d}
$$

Driveshaft is the last part of the transmission system which delivers the differentials torque to each wheel. A constant velocity joint is located at each end of the driveshafts to compensate the relative motion between the differential and wheel $[150,151]$. The efficiency of the drive shaft, which is dependent on the constant velocity joints (i.e., tripod and Rzeppa), is obtained by (11).

$$
\eta_{\text {dsh }}=\eta_{\text {Tripod }} \times \eta_{\text {Rzeppa }}
$$

Considering the efficiency of each part of a mechanical drivetrain system for an in-body transmission system, the total efficiency is obtained by (12).

$$
\eta_{\text {drivetrain }}=\eta_{g b o x} \times \eta_{p s h} \times \eta_{\text {diff }} \times \eta_{d s h}
$$

Note that the obtained efficiencies for each part are not constant in practice and they highly depend on the temperature of these parts and the operating speed [152]. For instance, the bearings efficiency of each part is at its lowest value in low temperature (high viscosity of oil) and highest operating speed. Or the universal joint and driveshaft efficiencies are changed by the offset (angle) between their ends. The offset for the universal joint is the angle between the front and rear angles, whereas the offset for the driveshaft is the angle between the differential and wheels. Literature shows the significance of the speed in determination the transmission system efficiency [153] in comparison to the role of other factors. It has been shown that the maximum efficiency of the transmission systems is not higher than $95 \%[144,153]$. Thus, this portion of the loss must not be ignored when the total efficiency of an EV is studied.

In the multi-speed transmissions, the friction, viscous, and clutch losses during changing from single to two or more is about $4 \%$ to $5 \%$ [154]. The losses per gear is $2 \%$ to $3 \%$ [154]. According to the comparative study results presented in [154], the efficiency of single, two, and three-speed transmission systems are $93 \%, 86 \%$, and $83 \%$, respectively.

\subsubsection{Losses and Efficiency in CVT}

The drive and driven pulleys are the main components of a CVT which are connected to each other through a metal belt [155]. As shown in Figure 10c, CVT delivers power to the wheels through a reduction gear [142]. Literature shows the CVT efficiency depends on the torque and speed ratio. Figure 11 shows how different portion of losses in CVT vary during various loading. This figure demonstrates the low efficiency of the CVT in small torque (i.e., 79\%). Additionally, it is seen that the CVT efficiency is reduced by increment of the speed ratio. A simple comparison between the efficiency of the multistage transmission system and the CVT shows their maximum efficiency is not larger than $95 \%$ in various torque-speed operating points [154]. 


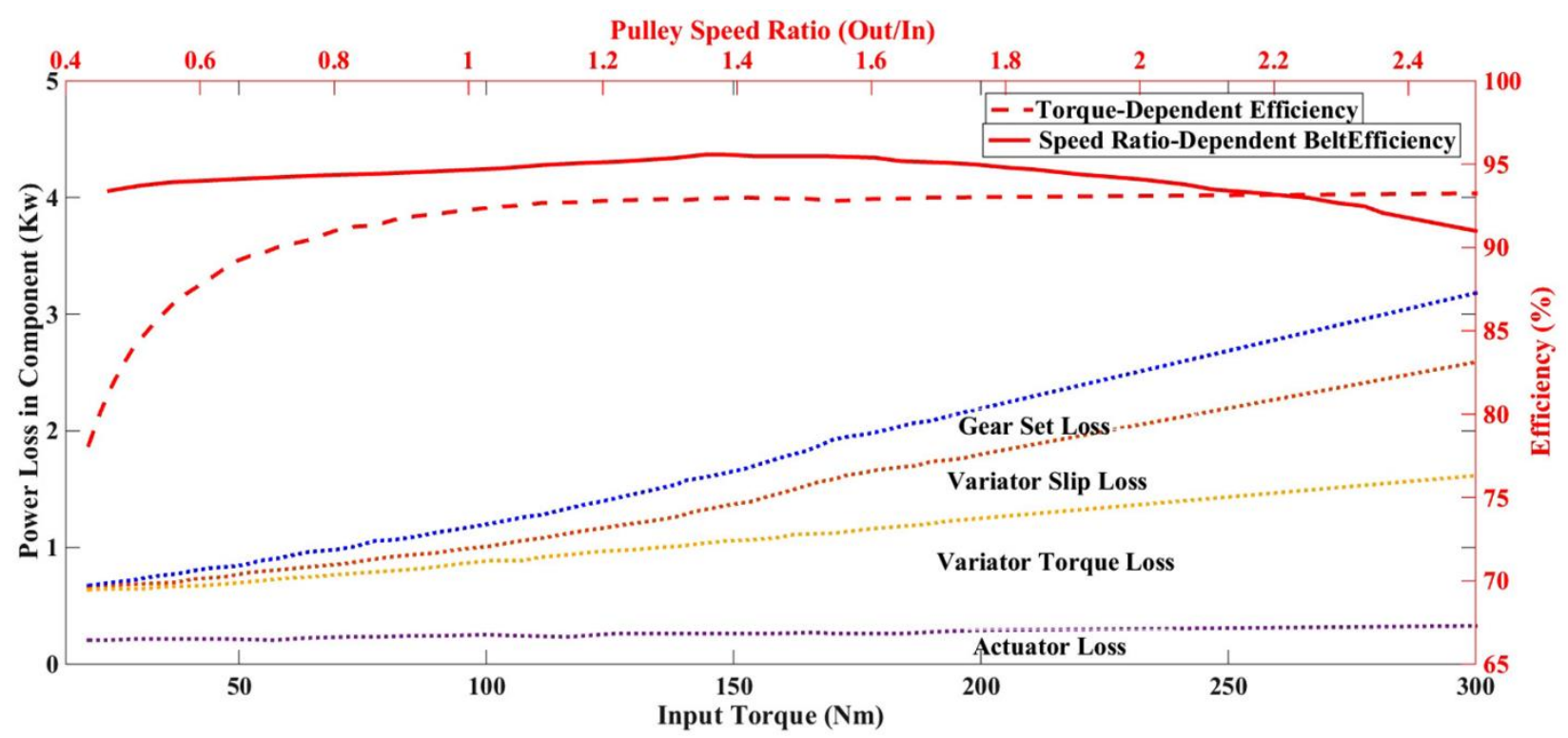

Figure 11. The variation of the losses and efficiency in CVT [154].

\subsubsection{Loss and Efficiency for In-Wheel Transmission System}

A reducer is used in the topology of the in-wheel EVs to utilize the electric machine in its field weakening region where it offers a high efficiency. The topology of the integration of the reducer with an in-wheel electric machine is explained in [143] (see Figure 2 in page 23 of [143]). According to this figure, the input shaft of the reducer is connected to the shaft of electric machine and its output shaft delivers power to the wheel. Figures 4 and 5 of page 25 in [143] presents the efficiency map of a reducer in the torque-speed envelope. As shown in these contour plots the efficiency of the reducer is larger than $95 \%$ which is higher than efficiency of the multi-speed transmission systema and CVTs used of in-body drivetrains. Hence, the use of in-wheel drivetrain in the EVs have found popularity among researchers and industries [156].

\subsection{Discussion on the Loss Analysis}

Literature show that the efficiency map and loss map of a certain electric machines can be scaled up and down for different power ratings [53,56,157]. Therefore, it is possible to estimate the losses over a driving cycle based on the scaling laws for different power ratings of the machines [55,157]. According to Equations (3) to (12) in [55], core, ohmic, and PM losses of a PMSM have a direct relationship by variation of the machine stack length and diameter. Copper loss is proportional to the change of radial and axial directions. The core loss is proportional to the axial direction and square of the radial direction changes. PM loss has a relationship with the fourth and third power of the radian and axial direction changes, respectively. Therefore, the losses in the PM machines can be estimated based on the variation of the dimension of the machine for different power ratings when the rating torque/power of the machine is proportional to the axial direction and square of the radial direction changes. Based on the scaling, if the axial and radial dimensions of a machine become two times of a benchmark machine, the core, ohmic, and PM losses will be 6, 2, and 128 times larger than the losses of the losses of the benchmark machines. The scaling law for the IM is also discussed in [157] which determines the relationship of the ohmic and core losses with the variation of the machine geometry.

The variation and characteristics of each portion of the loss in an electric vehicle has been discussed in Section 2. The IM and PM machines are the most popular machines in EVs. Table 4 summarizes the percentage each type of loss for these two machines in the constant torque and field weakening regions. It must be highlighted that the reported values are not absolute and have been determined based on the available data in the 
collected references. The size of the wire and number of strands can change the ohmic losses in a specific design [158]. The type and thickness of the laminated materials can change the core losses [159]. The type of the magnet and their number of segments vary the PM losses [134]. The type of the switches, converter, and control system can lead to change of the converter loss [80,160]. Mechanical losses can be changed by the type of the bearings.

Table 4. Range of the variation each type of loss as a percentage of the maximum power of the machine in the constant torque and constant power regions for IMs and IPMSMs [19-21,53,80,87,89,141,143,159-161].

\begin{tabular}{cccccccc}
\hline $\begin{array}{c}\text { Operating } \\
\text { Regions }\end{array}$ & $\begin{array}{c}\text { Machine } \\
\text { Type }\end{array}$ & Ohmic Loss & Core Loss & PM Loss & $\begin{array}{c}\text { Converter } \\
\text { Loss }\end{array}$ & $\begin{array}{c}\text { Mechanical } \\
\text { Loss }\end{array}$ & $\begin{array}{c}\text { Transmission } \\
\text { System Loss }\end{array}$ \\
\hline Constant & PM & $0.1-13 \%$ & $0.01-1.5 \%$ & $0.001-0.5 \%$ & $0.01-6 \%$ & $0.1-1 \%$ & $5-6 \%$ \\
torque & IM & $0.1-15 \%$ & $0.01-2.5 \%$ & 0 & $0.01-7 \%$ & $0.1-1 \%$ & $5-6 \%$ \\
\hline Constant & PM & $0.1-5 \%$ & $1-15 \%$ & $0.001-1 \%$ & $1-12 \%$ & $0.5-3 \%$ & $4-15 \%$ \\
power & IM & $0.1-10 \%$ & $1-2.5 \%$ & 0 & $1.5-15 \%$ & $0.5-3 \%$ & $4-15 \%$ \\
\hline
\end{tabular}

Due to the availability of the rotor bars in IMs, the ohmic loss range of variation in IMs is larger than the PM machines. The winding current which determines the ohmic losses is increased by increment of the torque [31]. So, the minimum and maximum ohmic losses tabulated in Table 4 is the percentage of the ohmic loss in lower and higher torques, respectively. Because of the current constraints of the electric machines, the maximum current cannot pass through the winding in the filed weakening region. Hence, the maximum value of the ohmic loss in the constant power region is less than the constant torque region $[53,87]$.

As it is explained in Section 2.2, core loss is function of the voltage and frequency. For this reason, it is seen that the percentage of the core loss in the field weakening region is much larger than the core loss of the constant torque region for IPMSMs. Note that the SPM core loss is larger than the IPMSMs and its higher band can be increased to $18 \%$ of the maximum power at higher speeds [21,24]. The maximum value of the core losses in the IMs in both of constant torque and field weakening is similar. The larger frequency of the operation in the field weakening region increases the minimum core losses of IMs compared to the constant torque region.

PM losses are increased by increment of the speed because of the increase of the induced eddy current on PMs. In the SPM machines, the PM is closer to the windings which leads to the increment of the eddy current on their surface. For this reason, in the field weakening region the PM losses can be increased to $6 \%$ or even higher for SPMSMs [21].

The lower power factor of IMs compared to the PM motors leads to the increment of the converter losses in both constant torque and constant speed regions. The large DC-link voltage at the field weakening region increases the switching losses $[80,161]$.

Mechanical and transmission system losses are the other portion of losses in EVs which highly depend on the operating speed. As it is tabulated in Table 4, their values in the constant power region are much larger than those of value in constant power region $[141,143]$.

\section{Experimental Setup for Measurement of the Losses}

The experimental calculation of the losses is carried out based on the efficiency extraction IEEE and IEC standards (i.e., IEEE 1812, IEC60034-2-1-2A, IEEE 112, and IEC 60034-2-1-1B [90]). The flowchart of the calculation of the motor efficiency based on these methods are shown in Figure 12. In these methods, the speed and load are changed as such the machine meets its rated temperature. 
IEEE 1812 PMSM Load Test

start $\rightarrow$ set speed $\rightarrow$ set voltage \& load $\rightarrow$ Wait to reach the steady state temperature $\rightarrow$ Record measurements $\rightarrow$ end

(a)

IEC 60034-2-1 Method 2-1-2A PMSM and DC motors Input/Output

start $\rightarrow$ set speed, voltage, \& load $\longrightarrow$ Record measurements $\rightarrow$ end

(b)

IEEE 112 Method A and B IM

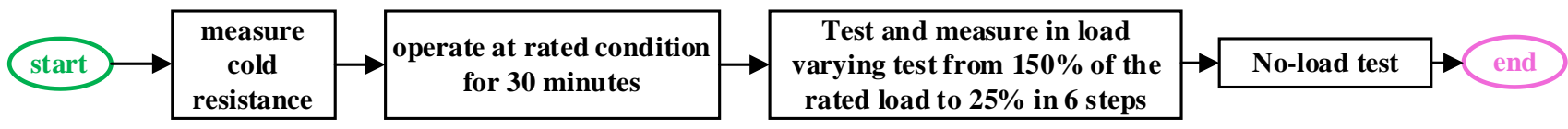

(c)

IEC 60034-2-1 Method 2-1-1B IM

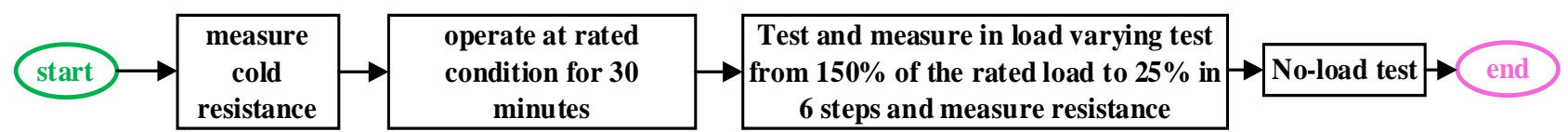

(d)

Figure 12. The conventional methods for the extraction of the motor's efficiency experimentally based on IEEE and IEC standards. (a) the procedure of the calculation of the efficiency at a certain load and speed for PMS motors based on IEEE standard. (b) the procedure of the calculation of the efficiency at a certain load and speed for PMS and DC motors based on IEC standard. (c) the procedure of the calculation of the efficiency at a certain load and speed for the induction motors based on IEEE standard. (d) the procedure of the calculation of the efficiency at a certain load and speed for the induction motors based on IEC standard.

Considering the standard methods for calculation of the electric machine efficiency, an experimental setup measuring the input and output power of the machine is required to find the machine losses by subtraction of the input power and output power. The efficiency and losses of each part of an EV drive system is found by proper placement of the measuring devices in the system. Figure 13 shows the entire drive-train system of an EV along with the monitoring/measuring devices which are required for experimental loss separation of the different parts.

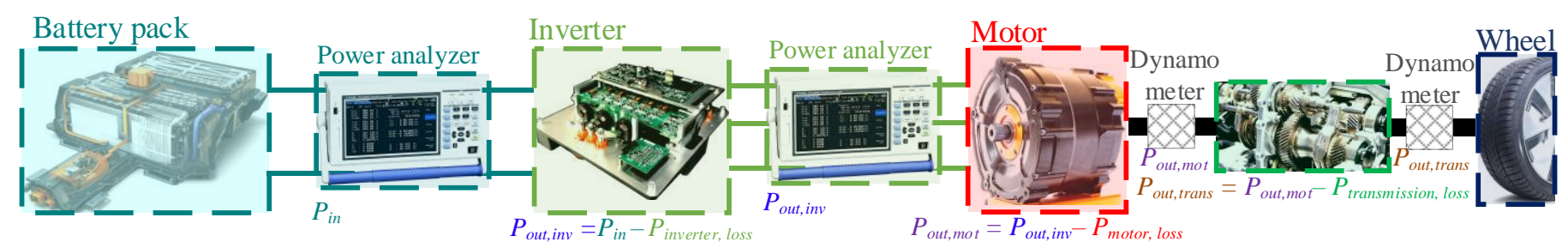

Figure 13. The placement of power analyzers and dynamo meters to measure each loss component of the EV propulsion system.

\subsection{Measurement of Converter Loss}

As shown in Figure 13, the converter losses are found by measuring the input power and output power of the converter using two power analyzers (the difference between the input power and output power results in the loss in the power converter).

\subsection{Electric Machine Loss}

Although the total machine loss is obtained by subtraction of the input and output power of the machine, the calculation of the split losses consisting of conductive, core, PM, and mechanical losses needs more details to be considered [2]. 


\subsubsection{Separation of Ohmic Losses}

In induction machines, ohmic losses result from the stator windings and rotor bars. A simple way for calculation of the ohmic losses is excitation of the windings at rated current in locked rotor condition [3]. The stator and rotor resistances are obtained by conducting this test. However, this method is not accurate for an inverter driven IM because the skin effect and harmonics are ignored if the measurement is done at a single operating point. Hence, it is suggested to supply the machine in different current levels and frequencies at locked rotor condition and measure the consumed active power which gives two variable resistances for both of stator windings and rotor bars.

The temperature rises, which lead to the increment of the resistance, should be considered. The temperature effect is considered by applying the DC test when the winding resistance is cold and when it is at the rated operating temperature. This variation of the measured resistance is considered as a coefficient to update the resistances from previous test (locked rotor). Having a variable stator and rotor resistance based on the frequencies allows to find the ohmic loss based on the EEC in different loadings. The rotor loss of the induction machine is proportional to the motor slip. In the next paragraphs, it will be explained that the core losses can be extracted independently from the slip. Therefore, the conductive rotor loss of induction motor is found by (13) when the stator resistance $\left(R_{S}\right)$, core loss $\left(P_{F e}\right)$, winding current $\left(I_{p h}\right)$, and slip $(s)$ are measured experimentally [162].

$$
P_{\text {rotor, } I M}=\left(\text { input power }-R_{s} I_{p h}^{2}-P_{F e}\right) s
$$

The resistance of the synchronous motors at different operating frequencies is found through a similar procedure. As the synchronous machines have no rotor bars, their rotor can be locked or even removed from the stator to extract the winding losses.

\subsubsection{Core Losses}

If the no-load input active power of the induction machine is subtracted by its no-load winding loss, the result is the summation of the core and mechanical losses. The standard tests for inverter driven machines segregate the core losses into two portions to investigate the harmonic effect separately $[163,164]$. The difference of the obtained core loss from the inverter driven machine with the extracted core loss when a pure sinusoidal supply the winding is determined as the core loss resulted from the harmonics.

The mechanical loss varies by speed. The core loss is a function of the voltage amplitude and frequency. If IM is run at a constant speed with different voltage levels, the interception point of the summation of core loss and mechanical loss (the measured input power of an electric machine at no-load condition) plot versus voltage square represents the mechanical loss. In other words, when the voltage is zero the machine loss just includes the mechanical loss of the machine at that speed. Note that at least a small amount of the voltage should be applied to the induction motor winding to reach the no-load speed. So, the experimental measurement of the mechanical loss when voltage is zero seems to be impossible. However, the machine at small supply voltage operates on the linear section of the B-H curve of the iron characteristic. Thus, to find the interception point with the y-axis (i.e., summation of the core and mechanical losses) it is logical to assume that the curve is linear and estimate the mechanical loss.

Applying the no-load test for determination of the core loss of the synchronous machines using a similar approach to the IM machine is a way to find the core and mechanical losses at different operating speeds and voltage levels. It has been proven that the core losses can be found using an open circuit test for synchronous PM machines. To apply the open circuit test, a prime mover rotates the shaft at a constant speed and the input mechanical power is recorded at each speed [165]. As the copper loss is zero, the measured mechanical power is equal to the summation of the core and mechanical losses of the synchronous PM machine. The mechanical and core losses are separated through the same approach explained for IM. 


\subsubsection{PM Losses for Permanent Magnet Motors}

The PM losses are another portion of the loss in the PM machines. There is an indirect technique for measurement of the PM losses. When the core loss, mechanical loss, and ohmic losses of a machine are extracted, the PM loss is found by subtraction of the total input power at loading condition with the summation of total output power and measured losses. To achieve a more accurate value for the PM losses through the indirect measurement technique, the ohmic losses of the stator should be collected when the rotor is removed from the stator. The indirect method is not accurate because some portion of the stray losses may be added to the PM loss. The amplitude and frequency of the induced eddy current on the PMs affects the PM temperature. In [166], the temperature of the PM parts was measured and (14) was used to find the PM losses.

$$
P_{P M}=\rho \times c \times N_{P M} \times V_{P M} \times\left(\frac{\Delta \theta}{\Delta t}\right)
$$

In this equation, $\rho$ and $c$ are the specific mass density and heat capacity of the PMs. Number of PM elements and volume of a single PM part are shown by $N_{P M}$ and $V_{P M}$. The rate of the variation of the temperature shown by $\frac{\Delta \theta}{\Delta t}$ which can be taken directly from the measured temperature variation curve.

\subsection{Transmission System Losses}

The transmission system losses are the last portion of the loss in the propulsion system of an EV. As shown in Figure 13, this portion is obtained by subtraction of the mechanical input power to the transmission system and its mechanical output power.

The EM of electric machines is accurate if it is plotted by 300 to 1600 points $[167,168]$. On the other hand, the efficiency map calculation requires a sweep between different pairs of $d$ - and $q$-axes currents to find the minimum loss point for each set of torque and speed. Thus, the loss separation over a driving cycle would be a time-consuming process because an accurate loss map for each portion of the loss is obtained when at least the above-mentioned details are considered for 300 operating points over a driving cycle.

\section{Research Gaps and Future Opportunities}

In addition to the electric machine losses, the power converter and transmission system losses have a significant value as a part of a propulsion system of an EV. Therefore, all types of the losses must be modeled with an acceptable accuracy for design of an optimal electric machines for EVs. The review shows that many studies have been conducted on the estimation of the copper and core losses in electric machines. However, the power converter losses, PM losses, and transmission losses which can significantly change during operation at high speeds on a wide torque-speed range have not been studied sufficiently.

Most of the proposed analytical models for the copper and core losses ignore the effect of the higher order harmonics of the power converters injected to the windings. So, the improvement of the accuracy of the losses based for the inverter driven machines in a wide torque speed range is an important topic of study. The optimal machine design can consider the inverter model to improve the efficiency. The switching modes of the inverters can be optimized to maximize the efficiency over a driving cycle.

Most of the analytical design methods of the electric machines ignore the converter losses which play an important role especially at higher speeds. Therefore, accurate modelling of the converter losses can be a prominent topic of the study. Adding an additional term to the loss function, proposed in [21], can be considered as a possible way for estimation of converter losses.

Literature has covered the role of cross-saturation to improve the calculation of the efficiency maps for synchronous machines [31]. The cross-saturation effect on the loss of the induction machine is small but can be studied to improve the calculated efficiency.

Temperature has a significant role on the amount of each loss component. As discussed in [22], multi-physics simulation environment and computationally expensive 
numerical methods are the main challenges of the consideration of the temperature effect in analytically calculated EMs. The investigation of the loss variation with the temperature and the accurate thermal analytical models are other significant subjects for future works.

Most of the conducted studies overlook the effect of the high order harmonics of the induced current on the PM parts, temperature effect, and variation of the physical characteristics of the PMs in different temperatures. The utilization of the multi-physics finite-element software to model the electromagnetics behavior of the PM machines along with the thermal and structural variations (i.e., any change in the shape of PMs and air barriers) in different speeds is useful to improve the accuracy of the PM loss modelling. The need of the computationally expensive 3D FEA simulation for the accurate estimation of the PM losses restricts the researchers to study PM losses in the torque-speed envelope of the electric machines. Introduction of a fast combined analytical-FEA method or an accurate loss function is helpful to model PM loss in a wide torque speed range.

The computational intelligence modelling and machine learning approaches have recently found popularity because of their ability in prediction and estimation of the physical characteristics of a system based on the real datasets. Some literature has used large datasets to predict losses and efficiency maps of electric machines [63,95]. The required dataset for these models is huge which hardens the provision of the dataset. Moreover, the application of these models is limited to the type of the motor with a specific shape of the magnet, slots, and barriers. These models can be mixed with the analytical models to reduce the amount of the required data. Combination of the loss function and computational intelligence models is another useful approach to develop a precise computational method for loss estimation of the electric machines with different sizes in a wide torque-speed range.

\section{Conclusions}

In this paper, it was explained that the design of electric machines to achieve the maximum efficiency requires an accurate prediction of the losses. To design the machine for optimal operation over a driving cycle, the loss prediction is more challenging because of the dependency of the losses on different operating points and supplying factors.

The dependency of each loss component on the efficiency of the electric machines at different operating regions was reviewed. The machine loss measurement and calculation methods were explained. The difference between the loss variation in different electric machines were described to show the weakness and strength of different electric machines for operation over a wide torque-speed range.

In addition to the electric machines, power converters play an important role in the drivetrain system of electric vehicles. Hence, the role of the converter losses and their significance in the total efficiency of the propulsion system of in EV was discussed. It was explained that the converter losses become significance when the electric machine operates at higher speeds.

The transmission systems of EVs were briefly reviewed. The specification of each transmission system in terms of loss and efficiency were discussed. Literature review determined the significance of the proper selection of the transmission system in EVs.

Based on the conducted literature review, the design of an optimal propulsion system for EVs needs many considerations. On one hand, the electric machines offer a high efficiency when they operate in higher speeds (field weakening region). On the other hand, the efficiency of the power converters and transmission systems are reduced by increment of the speed. Thus, it is necessary to investigate the performance of all section of an EV propulsion system during the design process.

The research gaps based on the conducted literature review were highlighted and the possible future research subjects in loss analysis of electric machines were introduced. It was explained that how the computational intelligence models help the loss prediction in the electric machines. 
Author Contributions: Conceptualization, E.R. and A.M.; methodology, E.R.; validation, E.R., S.K. and A.M.; formal analysis, A.M., S.K. and A.Y.; investigation, E.R.; resources, S.K. and A.M.; data curation, E.R.; writing-original draft preparation, E.R.; writing—review and editing, A.M., S.K., G.S. and A.Y.; visualization, E.R.; supervision, A.M.; project administration, A.M. All authors have read and agreed to the published version of the manuscript.

Funding: The paper has not been supported by any funding resources.

Institutional Review Board Statement: Not applicable.

Informed Consent Statement: Not applicable.

Data Availability Statement: Not applicable.

Conflicts of Interest: The authors declare no conflict of interest. The funders had no role in the design of the study; in the collection, analyses, or interpretation of data; in the writing of the manuscript, or in the decision to publish the results.

\section{References}

1. Mistry, R.; Finley, W.R.; Gaerke, T. Comparison of IEC and NEMA Requirements to Ensure Proper Specification and Design of Induction Motors \& Generators for Global use-Part 2: Paper No. PCIC-2017-04. In Proceedings of the 2018 IEEE Petroleum and Chemical Industry Technical Conference (PCIC), Cincinnati, OH, USA, 24-26 September 2018; pp. 29-38.

2. International Electrotechnical Commission. IEC 60034-1: Rotating Electrical Machines, Part 1: Rating and Performance; International Electrotechnical Commission: London, UK, 2010.

3. International Electrotechnical Commission. Rotating Electrical Machines-Part 2-1: Standard Methods for Determining Losses and Efficiency from Tests (Excluding Machines for Traction Vehicles); Standard No IEC 60034-2-1; International Electrotechnical Commission: London, UK, 2014.

4. A.T.I. Energy Efficiency Regulation of Electric Motors, Sydney. Available online: https://www.energyrating.gov.au/sites/ default/files/2020-01/motors_issues_paper_-_january_2020_0.pdf (accessed on 4 March 2021).

5. Zhang, B.; Guo, S.; Zhang, X.; Xue, Q.; Teng, L. Adaptive smoothing power following control strategy based on an optimal efficiency map for a hybrid electric tracked vehicle. Energies 2020, 13, 1893. [CrossRef]

6. Wolff, S.; Kalt, S.; Bstieler, M.; Lienkamp, M. Influence of Powertrain Topology and Electric Machine Design on Efficiency of Battery Electric Trucks-A Simulative Case-Study. Energies 2021, 14, 328. [CrossRef]

7. Verbruggen, F.J.R.; Silvas, E.; Hofman, T. Electric powertrain topology analysis and design for heavy-duty trucks. Energies 2020, 13, 2434. [CrossRef]

8. Gu, W.; Zhu, X.; Quan, L.; Du, Y. Design and optimization of permanent magnet brushless machines for electric vehicle applications. Energies 2015, 8, 13996-14008. [CrossRef]

9. Mahmoudi, A.; Rahim, N.A.; Hew, W.P. An analytical complementary FEA tool for optimizing of axial-flux permanent-magnet machines. Int. J. Appl. Electromagn. Mech. 2011, 37, 19-34. [CrossRef]

10. Dianati, B.; Kahourzade, S.; Mahmoudi, A. Axial-Flux Induction Motors for Electric Vehicles. In Proceedings of the 2019 IEEE Vehicle Power and Propulsion Conference (VPPC), Hanoi, Vietnam, 14-17 October 2019; pp. 1-6. [CrossRef]

11. Mahmoudi, A.; Kahourzade, S.; Roshandel, E.; Soong, W.L. Axial-Flux Synchronous Reluctance Motors: Introduction of a New Machine. In Proceedings of the 2020 IEEE International Conference on Power Electronics, Drives and Energy Systems (PEDES), Jaipur, India, 16-19 December 2020; pp. 1-6.

12. Roshandel, E.; Namazi, M.M.; Rashidi, A.; Saghaian-Nejad, S.M.; Ahn, J.-W. SSC strategy for SRG to achieve maximum power with minimum current ripple in battery charging. IET Electr. Power Appl. 2017, 11, 1205-1213. [CrossRef]

13. Roshandel, E.; Mahmoudi, A.; Kahourzade, S.; Soong, W.L. Design and Analysis of Small Aspect-Ratio Switched Reluctance Motor. In Proceedings of the 2020 IEEE International Conference on Power Electronics, Drives and Energy Systems (PEDES), Jaipur, India, 16-19 December 2020; pp. 1-6.

14. Roshandel, E.; Gheasaryan, S.M.; Saghaian-Nejad, S.M. A novel control strategy based on fuzzy logic for switched reluctance machine in battery charging mode. In Proceedings of the 2015 2nd International Conference on Knowledge-Based Engineering and Innovation (KBEI), Tehran, Iran, 5-6 November 2015; pp. 813-818.

15. Sarlioglu, B.; Morris, C.T.; Han, D.; Li, S. Benchmarking of electric and hybrid vehicle electric machines, power electronics, and batteries. In Proceedings of the 2015 International Aegean Conference on Electrical Machines \& Power Electronics (ACEMP), 2015 International Conference on Optimization of Electrical \& Electronic Equipment (OPTIM) \& 2015 International Symposium on Advanced Electromechanical Motion Systems (ELECTROMOTION), Side, Turkey, 2-4 September 2015; pp. 519-526. [CrossRef]

16. Yamazaki, K.; Abe, A. Loss investigation of interior permanent-magnet motors considering carrier harmonics and magnet eddy currents. IEEE Trans. Ind. Appl. 2009, 45, 659-665. [CrossRef]

17. Yamazaki, K.; Kuramochi, S. Additional harmonic losses of induction motors by PWM inverters: Comparison between result of finite element method and IEC/TS 60034. In Proceedings of the 2012 20th International Conference on Electrical Machines, Marseille, France, 2-5 September 2012; Volume 1, pp. 1552-1558. [CrossRef] 
18. Yamazaki, K.; Watari, S. Loss analysis of permanent-magnet motor considering carrier harmonics of PWM inverter using combination of 2-D and 3-D finite-element method. IEEE Trans. Magn. 2005, 41, 1980-1983. [CrossRef]

19. Kahourzade, S.; Mahmoudi, A.; Soong, W.L.; Ferrari, S.; Pellegrino, G. Correction of finite-element calculated efficiency map using experimental measurements. In Proceedings of the 2019 IEEE Energy Conversion Congress and Exposition (ECCE), Baltimore, MD, USA, 29 September-3 October 2019; pp. 5629-5636. [CrossRef]

20. Kahourzade, S.; Mahmoudi, A.; Soong, W.L.; Ertugrul, N.; Pellegrino, G. Estimation of PM Machine Efficiency Maps from Limited Data. IEEE Trans. Ind. Appl. 2020, 56, 2612-2621. [CrossRef]

21. Mahmoudi, A.; Soong, W.L.; Pellegrino, G.; Armando, E. Efficiency maps of electrical machines. In Proceedings of the 2015 IEEE Energy Conversion Congress and Exposition (ECCE), Montreal, QC, Canada, 20-24 September 2015; pp. 2791-2799. [CrossRef]

22. Wrobel, R.; Mellor, P.H.; Popescu, M.; Staton, D.A. Power loss analysis in thermal design of electrical machines. In Proceedings of the 2015 IEEE Workshop on Electrical Machines Design, Control and Diagnosis (WEMDCD), Turin, Italy, 26-27 March 2015; pp. 118-126. [CrossRef]

23. Dianati, B.; Kahourzade, S.; Mahmoudi, A. Optimization of Axial-Flux Induction Motors for the Application of Electric Vehicles Considering Driving Cycles. IEEE Trans. Energy Convers. 2020, 35, 1522-1533. [CrossRef]

24. Kahourzade, S.; Mahmoudi, A.; Soong, W.L.; Ertugrul, N.; Pellegrino, G. Estimation of PM Machine Efficiency Maps from Limited Experimental Data. In Proceedings of the 2018 IEEE Energy Conversion Congress and Exposition (ECCE), Portland, OR, USA, 23-27 September 2018; pp. 4315-4322. [CrossRef]

25. Takeno, M.; Ogasawara, S.; Chiba, A.; Takemoto, M.; Hoshi, N. Power and efficiency measurements and design improvement of a $50 \mathrm{~kW}$ switched reluctance motor for Hybrid Electric Vehicles. In Proceedings of the 2011 IEEE Energy Conversion Congress and Exposition, Phoenix, AZ, USA, 17-22 September 2011; pp. 1495-1501. [CrossRef]

26. Morandin, M.; Ferrari, M.; Bolognani, S. Power-Train Design and Performance of a Hybrid Motorcycle Prototype. IEEE Trans. Ind. Appl. 2015, 51, 2216-2226. [CrossRef]

27. Aguilera, F.; de la Barrera, P.M.; de Angelo, C.H. Selection of Induction Machine Models for Efficiency Evaluation in Electric Vehicles. IEEE Lat. Am. Trans. 2013, 11, 334-340. [CrossRef]

28. Chan, C.C.; Chau, K.T.; Jiang, J.Z.; Xia, W.; Zhu, M.; Zhang, R. Novel permanent magnet motor drives for electric vehicles. IEEE Trans. Ind. Electron. 1996, 43, 331-339. [CrossRef]

29. Sepe, R.B.; Miller, J.M.; Gale, A.R. Intelligent efficiency mapping of a hybrid electric vehicle starter/alternator using fuzzy logic. In Proceedings of the Gateway to the New Millennium. 18th Digital Avionics Systems Conference Proceedings (Cat. No.99CH37033), St. Louis, MO, USA, 24-29 October 1999; Volume B.6-6, pp. 8.B.2-1-8.B.2-8. [CrossRef]

30. Lukic, S.M.; Emado, A. Modeling of electric machines for automotive applications using efficiency maps. In Proceedings of the Electrical Insulation Conference and Electrical Manufacturing and Coil Winding Technology Conference (Cat. No.03CH37480), Indianapolis, IN, USA, 25 September 2003; pp. 543-550. [CrossRef]

31. Roshandel, E.; Mahmoudi, A.; Kahourzade, S. 2D Subdomain Model of the Ladder Linear Induction Machine with considering Saturation Effect. In Proceedings of the 2021 IEEE Energy Conversion Congress and Exposition (ECCE), Vancouver, BC, Canada, 10-14 October 2021; pp. 4127-4134. [CrossRef]

32. Kahourzade, S.; Mahmoudi, A.; Soong, W.L.; Pellegrino, G. A Practical Method for Estimating Efficiency Maps for PM Machines Using a Reduced Number of Tests. In Proceedings of the 2019 IEEE Vehicle Power and Propulsion Conference (VPPC), Hanoi, Vietnam, 14-17 October 2019; pp. 1-6. [CrossRef]

33. To, T.T.; Roshandel, E.; Mahmoudi, A.; Cao, Z.; Kahourzade, S. Optimization of IM Rotor Bars Inclination Angle using Analytical Model in Free FEA Software. In Proceedings of the 2021 IEEE Energy Conversion Congress and Exposition (ECCE), Vancouver, BC, Canada, 10-14 October 2021; pp. 4119-4126. [CrossRef]

34. Ansys ${ }^{\circledR E}$ Electromagnetics. 2021. Available online: https://www.ansys.com/academic/terms-and-conditions (accessed on 31 July 2021).

35. Bacco, G.; Babetto, C.; Bonfante, M.; Carbonieri, M.; Bianchi, N. Efficiency Maps Computation and Comparison Including Thermal Limits. In Proceedings of the 2019 IEEE Energy Conversion Congress and Exposition (ECCE), Baltimore, MD, USA, 29 September-3 October 2019; pp. 4846-4852. [CrossRef]

36. Palka, R.; Paplicki, P.; Wardach, M.; Bonislawski, M. Hybrid excited machine for electric vehicles propulsion. In Proceedings of the 2018 International Symposium on Electrical Machines (SME), Andrychow, Poland, 10-13 June 2018; pp. 21-24. [CrossRef]

37. Liu, X.; Zhu, Z.Q.; Wu, D. Evaluation of efficiency optimized variable flux reluctance machine for EVs/HEVs by comparing with interior PM machine. In Proceedings of the 2014 17th International Conference on Electrical Machines and Systems (ICEMS), Hangzhou, China, 22-25 October 2014; pp. 2648-2654. [CrossRef]

38. An, J.; Binder, A. Design of interior permanent magnet synchronous machine for two-drive-transmission. In Proceedings of the 2015 International Conference on Electrical Systems for Aircraft, Railway, Ship Propulsion and Road Vehicles (ESARS), Aachen, Germany, 3-5 March 2015; pp. 1-6. [CrossRef]

39. Vincent, R.; Emmanuel, V.; Lauric, G.; Laurent, G. Optimal sizing of an electrical machine using a magnetic circuit model: Application to a hybrid electrical vehicle. IET Electr. Syst. Transp. 2016, 6, 27-33. [CrossRef]

40. Hsu, J.S.; Burress, T.A.; Lee, S.T.; Wiles, R.H.; Coomer, C.L.; McKeever, J.W.; Adams, D.J. 16,000-RPM Interior Permanent Magnet Reluctance Machine with Brushless Field Excitation. In Proceedings of the 2008 IEEE Industry Applications Society Annual Meeting, Edmonton, AB, Canada, 5-9 October 2008; pp. 1-6. [CrossRef] 
41. Ciampolini, M.; Ferrara, G.; Fazzini, L.; Pugi, L.; Berzi, L. Simplified Approach for Developing Efficiency Maps of High-Speed PMSM Machines for Use in EAT Systems Starting from Single-Point Data. In Proceedings of the 2020 IEEE International Conference on Environment and Electrical Engineering and 2020 IEEE Industrial and Commercial Power Systems Europe (EEEIC/I\&CPS Europe), Madrid, Spain, 9-12 June 2020.

42. Gosden, D.F. Drive system design for an electric vehicle based on alternative motor types. In Proceedings of the 5th International Conference on Power Electronics and Variable-Speed Drives, London, UK, 26-28 October 1994; Volume 1994, pp. 710-715. [CrossRef]

43. Mokhtari, H.; Tara, E. Efficiency map of a Switched Reluctance Motor using Finite Element Method in vehicular applications. In Proceedings of the 2007 7th Internatonal Conference on Power Electronics, Daegu, Korea, 22-26 October 2007; pp. 644-649. [CrossRef]

44. Yajima, S.; Takemoto, M.; Tanaka, Y.; Chiba, A.; Fukao, T. Total Efficiency of a Deeply Buried Permanent Magnet Type Bearingless Motor Equipped with 2-pole Motor Windings and 4-pole Suspension Windings. In Proceedings of the 2007 IEEE Power Engineering Society General Meeting, Tampa, FL, USA, 24-28 June 2007; pp. 1-7. [CrossRef]

45. Liu, R.; Zhao, H.; Zheng, P.; Gan, X.; Zhao, R.; Kou, B. Experimental evaluation of a radial-radial-flux compound-structure permanent-magnet synchronous machine used for HEVs. In Proceedings of the 2008 14th Symposium on Electromagnetic Launch Technology, Victoria, BC, Canada, 10-13 June 2008; pp. 1-5.

46. Zheng, P.; Liu, R.; Wu, Q.; Tong, C.; Tang, Z. Compound-structure permanent-magnet synchronous machine used for HEVs. In Proceedings of the 2008 International Conference on Electrical Machines and Systems, Wuhan, China, 17-20 October 2008; pp. 2916-2920. Available online: https:/ / ieeexplore.ieee.org/document/4771252 (accessed on 5 June 2021).

47. Jung, H.C.; Kim, D.J.; Jung, S.Y.; Lee, D. Optimization Method to Maximize Efficiency Map of a Drive Motor with Electrical Winding Changeover Technique for Hybrid EV. IEEE Trans. Appl. Supercond. 2020, 30, 5205405. [CrossRef]

48. Rahman, S.A.; Knight, A.M. Performance and core loss of concentrated winding IPMSM with different core treatment. In Proceedings of the 2014 IEEE Energy Conversion Congress and Exposition (ECCE), Pittsburgh, PA, USA, 14-18 September 2014; pp. 5587-5594. [CrossRef]

49. Chu, W.Q.; Zhu, Z.Q.; Zhang, J.; Ge, X.; Liu, X.; Stone, D.; Foster, M. Comparison of electrically excited and interior permanent magnet machines for hybrid electric vehicle application. In Proceedings of the 2014 17th International Conference on Electrical Machines and Systems (ICEMS), Hangzhou, China, 22-25 October 2014; pp. 401-407. [CrossRef]

50. Chu, W.Q.; Zhu, Z.Q.; Zhang, J.; Liu, X.; Stone, D.A.; Foster, M.P. Investigation on operational envelops and efficiency maps of electrically excited machines for electrical vehicle applications. IEEE Trans. Magn. 2015, 51, 8103510. [CrossRef]

51. Kato, T.; Minowa, M.; Hijikata, H.; Akatsu, K.; Lorenz, R.D. Design Methodology for Variable Leakage Flux IPM for Automobile Traction Drives. IEEE Trans. Ind. Appl. 2015, 51, 3811-3821. [CrossRef]

52. Yang, Z.; Shang, F.; Brown, I.P.; Krishnamurthy, M. Comparative study of interior permanent magnet, induction, and switched reluctance motor drives for EV and HEV applications. IEEE Trans. Transp. Electrif. 2015, 1, 245-254. [CrossRef]

53. Zhou, K.; Ivanco, A.; Filipi, Z.; Hofmann, H. Finite-Element-Based Computationally Efficient Scalable Electric Machine Model Suitable for Electrified Powertrain Simulation and Optimization. IEEE Trans. Ind. Appl. 2015, 51, 4435-4445. [CrossRef]

54. Mahmoudi, A.; Soong, W.L.; Pellegrino, G.; Armando, E. Loss Function Modeling of Efficiency Maps of Electrical Machines. IEEE Trans. Ind. Appl. 2017, 53, 4221-4231. [CrossRef]

55. Stipetic, S.; Goss, J. Calculation of efficiency maps using scalable saturated flux-linkage and loss model of a synchronous motor. In Proceedings of the 2016 22th International Conference on Electrical Machines (ICEM), Lausanne, Switzerland, 4-7 September 2016; pp. 1380-1386. [CrossRef]

56. Stipetic, S.; Goss, J.; Zarko, D.; Popescu, M. Calculation of Efficiency Maps Using a Scalable Saturated Model of Synchronous Permanent Magnet Machines. IEEE Trans. Ind. Appl. 2018, 54, 4257-4267. [CrossRef]

57. Dück, P.; Ponick, B. A novel iron-loss-model for permanent magnet synchronous machines in traction applications. In Proceedings of the 2016 International Conference on Electrical Systems for Aircraft, Railway, Ship Propulsion and Road Vehicles \& International Transportation Electrification Conference (ESARS-ITEC), Toulouse, France, 2-4 November 2016. [CrossRef]

58. Lopez-Torres, C.; Colls, C.; Garcia, A.; Riba, J.R.; Romeral, L. Development of a Behavior Maps Tool to Evaluate Drive Operational Boundaries and Optimization Assessment of PMa-SynRMs. IEEE Trans. Veh. Technol. 2018, 67, 6861-6871. [CrossRef]

59. Shah, S.B.; Arkkio, A. Efficiency map prediction of flux switching machine. In Proceedings of the 2015 18th International Conference on Electrical Machines and Systems (ICEMS), Pattaya, Thailand, 25-28 October 2015; pp. 1490-1493. [CrossRef]

60. Hruska, K.; Dvorak, P. The Validity Range of PMSM Efficiency Map Regarding Its Equivalent Circuit Parameters. 2016, pp. 1-7. Available online: https:/ / ieeexplore.ieee.org/document/7827817 (accessed on 20 May 2021).

61. Ruba, M.; Jurca, F.; Martis, C. Analysis of synchronous reluctance machine for light electric vehicle applications. In Proceedings of the 2016 International Symposium on Power Electronics, Electrical Drives, Automation and Motion (SPEEDAM), Capri, Italy, 22-24 June 2016; pp. 1138-1143. [CrossRef]

62. Lu, C.; Ferrari, S.; Pellegrino, G. Two Design Procedures for PM Synchronous Machines for Electric Powertrains. IEEE Trans. Transp. Electrif. 2017, 3, 98-107. [CrossRef]

63. Mohammadi, M.H.; Lowther, D.A. A Computational Study of Efficiency Map Calculation for Synchronous AC Motor Drives Including Cross-Coupling and Saturation Effects. IEEE Trans. Magn. 2017, 53, 8103704. [CrossRef] 
64. Li, K.; Cui, S.; Bouscayrol, A.; Hecquet, M. Analytical derivation of efficiency map of an induction machine for electric vehicle applications. In Proceedings of the 2018 IEEE Vehicle Power and Propulsion Conference (VPPC), Chicago, IL, USA, 27-30 August 2018; pp. 1-6. [CrossRef]

65. Pinhal, D.B.; Gerling, D. Performance Map Calculation of a Salient-Pole Synchronous Motor with Hairpin Winding. In Proceedings of the 2019 IEEE 28th International Symposium on Industrial Electronics (ISIE), Vancouver, BC, Canada, 12-14 June 2019; pp. 359-365. [CrossRef]

66. He, A.; Zhou, C.; Huang, X.; Shen, J.; Fang, Y.; Lu, Q. Evaluation of fractional slot concentrated winding permanent magnet synchronous machine for electric vehicle application. In Proceedings of the 2019 IEEE International Electric Machines \& Drives Conference (IEMDC), San Diego, CA, USA, 12-15 May 2019; pp. 988-992. [CrossRef]

67. Rassolkin, A.; Heidari, H.; Kallaste, A.; Vaimann, T.; Acedo, J.P.; Romero-Cadaval, E. Efficiency Map Comparison of Induction and Synchronous Reluctance Motors. In Proceedings of the 2019 26th International Workshop on Electric Drives: Improvement in Efficiency of Electric Drives (IWED), Moscow, Russia, 30 January-2 February 2019; pp. 26-29. [CrossRef]

68. Gonzalez, A.G.; Jha, A.K.; Li, Z.; Upadhayay, P.; Rasmussen, P. Validation of efficiency maps of an outer rotor surface mounted permanent magnet machine for evaluation of recyclability of magnets. In Proceedings of the 2018 IEEE International Magnetics Conference (INTERMAG), Singapore, 23-27 April 2018; pp. 1-6. [CrossRef]

69. Sepe, J.; Morrison, C.M.; Miller, J.M.; Gale, A.R. High efficiency operation of a hybrid electric vehicle starter/generator over road profiles. In Proceedings of the Conference Record of the 2001 IEEE Industry Applications Conference 36th IAS Annual Meeting (Cat. No. 01CH37248), Chicago, IL, USA, 30 September-4 October 2001; Volume 2, pp. 921-925. [CrossRef]

70. Materu, P.N.; Krishnan, R. Estimation of switched reluctance motor losses. IEEE Trans. Ind. Appl. 1992, 28, 668-679. [CrossRef]

71. Pugsley, G.; Chillet, C.; Fonseca, A.; Bui-Van, A.-L. New modeling methodology for induction machine efficiency mapping for hybrid vehicles. In Proceedings of the IEEE International Electric Machines and Drives Conference, IEMDC'03, Madison, WI USA, 1-4 June 2003; Volume 2, pp. 776-781. [CrossRef]

72. Finken, T.; Hombitzer, M.; Hameyer, K. Study and comparison of several permanent-magnet excited rotor types regarding their applicability in electric vehicles. In Proceedings of the 2010 Emobility-Electrical Power Train, Leipzig, Germany, 8-9 November 2010; pp. 1-7. [CrossRef]

73. Li, Z.; Miotto, A. Concentrated-winding fractional-slot synchronous surface PM motor design based on efficiency map for in-wheel application of electric vehicle. In Proceedings of the 2011 IEEE Vehicle Power and Propulsion Conference, Chicago, IL, USA, 6-9 September 2011; pp. 1-8. [CrossRef]

74. Stanislav, F.; Jan, B.; Jiri, L. Analytical derivation of induction machine efficiency map. In Proceedings of the 4th International Conference on Power Engineering, Energy and Electrical Drives, Istanbul, Turkey, 13-17 May 2013; pp. 1206-1210. [CrossRef]

75. Li, Q.; Fan, T.; Wen, X.; Tai, X.; Li, Y.; Zhang, G. Modeling of the efficiency MAP of surface permanent magnet machine for electrical vehicles. In Proceedings of the 2013 International Conference on Electrical Machines and Systems (ICEMS), Busan, Korea, 26-29 October 2013; pp. 1222-1225. [CrossRef]

76. Dlala, E.; Solveson, M.; Stanton, S.; Tang, Z.; Christini, M.; Ong, R.; Peaslee, B. Efficiency map simulations for an interior PM motor with experimental comparison and investigation of magnet size reduction. In Proceedings of the 2013 International Electric Machines \& Drives Conference, Chicago, IL, USA, 12-15 May 2013; pp. 23-29. [CrossRef]

77. Du, J.; Wang, X.; Lv, H. Optimization of Magnet Shape Based on Efficiency Map of IPMSM for EVs. IEEE Trans. Appl. Supercond. 2016, 26, 0609807. [CrossRef]

78. Novak, M.; Novak, J.; Novak, Z. Methodology for efficiency mapping of permanent magnet synchronous motors. In Proceedings of the 2017 19th International Conference on Electrical Drives and Power Electronics (EDPE), Dubrovnik, Croatia, 4-6 October 2017; pp. 205-210. [CrossRef]

79. Novak, M.; Novak, J.; Novak, Z.; Chysky, J.; Sivkov, O. Efficiency mapping of a 100 kW PMSM for traction applications. In Proceedings of the 2017 IEEE 26th International Symposium on Industrial Electronics (ISIE), Edinburgh, UK, 19-21 June 2017; pp. 290-295. [CrossRef]

80. Golzar, M.; van Khang, H.; Choux, M.M.H.; Versland, A.M.M. Experimental investigation of efficiency map for an inverter-fed surface-mount permanent magnet synchronous motor. In Proceedings of the 2019 8th International Conference on Renewable Energy Research and Applications (ICRERA), Brasov, Romania, 3-6 November 2019; pp. 551-556. [CrossRef]

81. Novak, M.; Novak, J. Test Setup with a Permanent Magnet Synchronous Machine for Efficiency Maps of an Electric Vehicle. In Proceedings of the 2018 23rd International Conference on Electrical Machines (ICEM), Alexandroupoli, Greece, 3-6 September 2018; pp. 1698-1703. [CrossRef]

82. Endress, T.; Bragard, M. Recording of efficiency-maps of low-power electric drive systems using a flexible Matlab-based test bench. In Proceedings of the 2017 IEEE 58th International Scientific Conference on Power and Electrical Engineering of Riga Technical University (RTUCON), Riga, Latvia, 12-13 October 2017; pp. 1-5. [CrossRef]

83. Zhang, Q.; Liu, X. Permanent Magnetic Synchronous Motor and drives applied on a mid-size hybrid electric car. In Proceedings of the 2008 IEEE Vehicle Power and Propulsion Conference, Harbin, China, 3-5 September 2008; pp. 1-5. [CrossRef]

84. Bazzi, A.M.; Krein, P.T. Comparative evaluation of machines for electric and hybrid vehicles based on dynamic operation and loss minimization. In Proceedings of the 2010 IEEE Energy Conversion Congress and Exposition, Atlanta, GA, USA, 12-16 September 2010; pp. 3345-3351. [CrossRef] 
85. Morandin, M.; Ferrari, M.; Bolognani, S. Design and performance of a power train for mild-hybrid motorcycle prototype. In Proceedings of the 2013 International Electric Machines \& Drives Conference, Chicago, IL, USA, 12-15 May 2013; pp. 1-8. [CrossRef]

86. Aguilera, F.; de la Barrera, P.M.; de Angelo, C.H. Induction machine models for efficiency studies in EV design applications. In Proceedings of the 2012 10th IEEE/IAS International Conference on Industry Applications, Fortaleza, Brazil, 5-7 November 2012; pp. 1-7. [CrossRef]

87. Guan, Y.; Zhu, Z.Q.; Afinowi, I.A.A.; Mipo, J.C.; Farah, P. Calculation of torque-speed characteristic of induction machine for electrical vehicle application using analytical method. In Proceedings of the 2014 International Conference on Electrical Machines (ICEM), Berlin, Germany, 2-5 September 2014; pp. 2715-2721. [CrossRef]

88. Williamson, S.; Lukic, M.; Emadi, A. Comprehensive drive train efficiency analysis of hybrid electric and fuel cell vehicles based on motor-controller efficiency modeling. IEEE Trans. Power Electron. 2006, 21, 730-740. [CrossRef]

89. Kollmeyer, P.J.; McFarland, J.D.; Jahns, T.M. Comparison of class 2a truck electric vehicle drivetrain losses for single- and two-speed gearbox systems with IPM traction machines. In Proceedings of the 2015 IEEE International Electric Machines \& Drives Conference (IEMDC), Coeur d'Alene, ID, USA, 10-13 May 2016; pp. 1501-1507. [CrossRef]

90. Haines, G.; Ertugrul, N.; Soong, W.L. Autonomously obtaining system efficiency maps from motor drive systems. In Proceedings of the 2019 IEEE International Conference on Industrial Technology (ICIT), Melbourne, VIC, Australia, 13-15 February 2019; pp. 231-236. [CrossRef]

91. Ade, M.; Binder, A. Modeling the drive train for two parallel Hybrid Electric Vehicles in MATLAB/Simulink. In Proceedings of the 2009 IEEE Vehicle Power and Propulsion Conference, Dearborn, MI, USA, 7-10 September 2009; pp. 592-600. [CrossRef]

92. Xiaoxu, W.; Sibo, W.; Mingian, C.; Huichao, Z. Efficiency testing technology and evaluation of the electric vehicle motor drive system. In Proceedings of the 2014 IEEE Conference and Expo Transportation Electrification Asia-Pacific (ITEC Asia-Pacific), Beijing, China, 31 August-3 September 2014; pp. 1-5. [CrossRef]

93. Depature, C.; Lhomme, W.; Bouscayrol, A.; Sicard, P.; Boulon, L. Efficiency Map of the Traction System of an Electric Vehicle from an On-Road Test Drive. In Proceedings of the 2014 IEEE Vehicle Power and Propulsion Conference (VPPC), Coimbra, Portugal, 27-30 October 2014; pp. 1-6. [CrossRef]

94. Sun, L.; Cheng, M.; Wen, H.; Song, L. Motion Control and Performance Evaluation of a Magnetic-Geared Dual-Rotor Motor in Hybrid Powertrain. IEEE Trans. Ind. Electron. 2017, 64, 1863-1872. [CrossRef]

95. Krasopoulos, C.T.; Beniakar, M.E.; Kladas, A.G. Multicriteria PM motor design based on ANFIS evaluation of EV driving cycle efficiency. IEEE Trans. Transp. Electrif. 2018, 4, 525-535. [CrossRef]

96. Cosovic, M.; Smaka, S. Design of initial topology of interior permanent magnet synchronous machine for hybrid electric vehicle. In Proceedings of the 2015 IEEE International Electric Machines \& Drives Conference (IEMDC), Coeur d'Alene, ID, USA, 10-13 May 2015; pp. 1658-1664. [CrossRef]

97. Steinmetz, C.P. On the law of hysteresis. Proc. IEEE 1984, 72, 197-221. [CrossRef]

98. Li, J.; Abdallah, T.; Sullivan, C.R. Improved calculation of core loss with nonsinusoidal waveforms. In Proceedings of the Conference Record of the 2001 IEEE Industry Applications Conference 36th IAS Annual Meeting (Cat. No. 01CH37248), Chicago, IL, USA, 30 September-4 October 2001; Volume 4, pp. 2203-2210.

99. Venkatachalam, K.; Sullivan, C.R.; Abdallah, T.; Tacca, H. Accurate prediction of ferrite core loss with nonsinusoidal waveforms using only Steinmetz parameters. In Proceedings of the 2002 IEEE Workshop on Computers in Power Electronics, Mayaguez, PR, USA, 3-4 June 2002; pp. 36-41.

100. Pry, R.H.; Bean, C.P. Calculation of the energy loss in magnetic sheet materials using a domain model. J. Appl. Phys. 1958, 29, 532-533. [CrossRef]

101. Bertotti, G. Physical interpretation of eddy current losses in ferromagnetic materials. I. Theoretical considerations. J. Appl. Phys. 1985, 57, 2110-2117. [CrossRef]

102. Bertotti, G. Physical interpretation of eddy current losses in ferromagnetic materials. II. Analysis of experimental results. J. Appl. Phys. 1985, 57, 2118-2126. [CrossRef]

103. Pluta, W.A. Some properties of factors of specific total loss components in electrical steel. IEEE Trans. Magn. 2010, 46, 322-325. [CrossRef]

104. Dianati, B.; Kahourzade, S.; Mahmoudi, A. Analytical Design of Axial-Flux Induction Motors. In Proceedings of the 2019 IEEE Vehicle Power and Propulsion Conference (VPPC), Hanoi, Vietnam, 14-17 October 2019; pp. 1-6. [CrossRef]

105. Emami, S.P.; Roshandel, E.; Mahmoudi, A.; Khaourzade, S. IPM Motor Optimization for Electric Vehicles Considering Driving Cycles. In Proceedings of the 2021 31st Australasian Universities Power Engineering Conference (AUPEC), Perth, WA, Australia, 26-30 September 2021; pp. 1-5. [CrossRef]

106. Zhu, Z.-Q.; Xue, S.; Chu, W.; Feng, J.; Guo, S.; Chen, Z.; Peng, J. Evaluation of iron loss models in electrical machines. IEEE Trans. Ind. Appl. 2018, 55, 1461-1472. [CrossRef]

107. Sippola, M.; Sepponen, R.E. Accurate prediction of high-frequency power-transformer losses and temperature rise. IEEE Trans. Power Electron. 2002, 17, 835-847. [CrossRef]

108. Ji, H.N.; Lan, Z.W.; Xu, Z.Y.; Zhang, H.W.; Yu, J.X.; Li, M.Q. Effects of second milling time on temperature dependence and improved Steinmetz parameters of low loss MnZn power ferrites. IEEE Trans. Appl. Supercond. 2014, 24, 7000104. [CrossRef] 
109. Zhao, Z.; Hu, X.; Bi, Z.; Xu, M.; Ma, X.; Zhang, P. Calculation of core loss under distorted flux density with minor hysteresis loops for laminated steel structure. AIP Adv. 2020, 10, 75001. [CrossRef]

110. Mayergoyz, I.D. Mathematical Models of Hysteresis and Their Applications; Elsevier Science Inc.: New York, NY, USA, 2003.

111. Jiles, D.C.; Atherton, D.L. Theory of ferromagnetic hysteresis. J. Magn. Magn. Mater. 1986, 61, 48-60. [CrossRef]

112. Dupre, L.R.; van Keer, R.; Melkebeek, J.A.A. An iron loss model for electrical machines using the Preisach theory. IEEE Trans. Magn. 1997, 33, 4158-4160. [CrossRef]

113. Benabou, A.; Clenet, S.; Piriou, F. Comparison of Preisach and Jiles-Atherton models to take into account hysteresis phenomenon for finite element analysis. J. Magn. Magn. Mater. 2003, 261, 139-160. [CrossRef]

114. Roshandel, E.; Mahmoudi, A.; Kahourzade, S.; Soong, W.L. Saturation Consideration in Modeling of the Induction Machine using Subdomain Technique to Predict Performance. IEEE Trans. Ind. Appl. 2021. [CrossRef]

115. Ansys Motor-CAD. Electric Machine Design Software. 2021. Available online: https://www.ansys.com/products/electronics/ ansys-motor-cad (accessed on 1 July 2021).

116. JMAG. JMAG: Simulation Technology for Electromechanical Design. Japan. 2021. Available online: https://www.jmaginternational.com/wp-content/uploads/products/pdf/catalog_en.pdf (accessed on 2 July 2021).

117. Corporation, J. JMAG Version 12 User's Manual Solver; JSOL Corporation: Osaka, Japan, 2013.

118. Krings, A.; Nategh, S.; Stening, A.; Grop, H.; Wallmark, O.; Soulard, J. Measurement and modeling of iron losses in electrical machines. In Proceedings of the 5th International Conference Magnetism and Metallurgy WMM'12, Ghent, Belgium, 20-22 June 2012; pp. 101-119.

119. Roshandel, E.; Mahmoudi, A.; Kahourzade, S.; Soong, W. Analytical Model and Performance Prediction of Induction Motors using Subdomain Technique. In Proceedings of the 2020 IEEE Energy Conversion Congress and Exposition (ECCE), Detroit, MI, USA, 11-15 October 2020; pp. 3815-3822. [CrossRef]

120. Kahourzade, S.; Mahmoudi, A.; Roshandel, E.; Cao, Z. Optimal design of Axial-Flux Induction Motors based on an improved analytical model. Energy 2021, 237, 121552. [CrossRef]

121. Cao, Z.; Mahmoudi, A.; Kahourzade, S.; Soong, W. Surface Permanent Magnet Machines: A Comparative Study (4-pole vs. 40-pole motor). In Proceedings of the 2020 IEEE International Conference on Power Electronics, Drives and Energy Systems (PEDES), Jaipur, India, 16-19 December 2020; pp. 1-6.

122. Gieras, J.F. Permanent Magnet Motor Technology: Design and Applications; CRC Press: Boca Raton, FL, USA, 2002.

123. Naderi, P.; Heidary, M.; Vahedi, M. Performance analysis of ladder-secondary-linear induction motor with two different secondary types using Magnetic Equivalent Circuit. ISA Trans. 2020, 103, 355-365. [CrossRef] [PubMed]

124. Tao, F.; Jian, L.; Xuhui, W.; Xiaofeng, L. A new sizing equation and it's application in electrical machine design. In Proceedings of the 2011 International Conference on Electric Information and Control Engineering, Wuhan, China, 15-17 April 2011; pp. 3890-3893.

125. Park, G.J.; Son, B.; Jung, S.Y.; Kim, Y.J. Reducing computational time strategy for estimating core loss with spatial and temporal periodicity. In Proceedings of the 2016 IEEE Transportation Electrification Conference and Expo, Asia-Pacific (ITEC Asia-Pacific), Busan, Korea, 1-4 June 2016; pp. 460-464. [CrossRef]

126. Eberle, W.; Zhang, Z.; Liu, Y.-F.; Sen, P.C. A simple analytical switching loss model for buck voltage regulators. In Proceedings of the 2008 Twenty-Third Annual IEEE Applied Power Electronics Conference and Exposition, Austin, TX, USA, 24-28 February 2008; pp. 36-42.

127. Gurpinar, E.; Ozpineci, B. Loss analysis and mapping of a sic mosfet based segmented two-level three-phase inverter for ev traction systems. In Proceedings of the 2018 IEEE Transportation Electrification Conference and Expo (ITEC), Long Beach, CA, USA, 13-15 June 2018; pp. 1046-1053.

128. Thoben, M.; Siepe, D.; Kriegel, K. Use of Power electronics for HEV at elevated temperature. In Proceedings of the Braunschweiger Hybridsymposium, Munich, Germany, 13-14 February 2008.

129. Wu, X.; Wrobel, R.; Mellor, P.H.; Zhang, C. A computationally efficient PM power loss derivation for surface-mounted brushless AC PM machines. In Proceedings of the 2014 International Conference on Electrical Machines (ICEM), Berlin, Germany, 2-5 September 2014; pp. 17-23.

130. Wu, X.; Wrobel, R.; Mellor, P.H.; Zhang, C. A computationally efficient PM power loss mapping for brushless AC PM machines with surface-mounted PM rotor construction. IEEE Trans. Ind. Electron. 2015, 62, 7391-7401. [CrossRef]

131. Lundmark, S.T.; Fard, P.R. Two-dimensional and three-dimensional core and magnet loss modeling in a radial flux and a transverse flux PM traction motor. IEEE Trans. Ind. Appl. 2017, 53, 2028-2039. [CrossRef]

132. Kahourzade, S.; Ertugrul, N.; Soong, W.L. Loss analysis and efficiency improvement of an axial-flux PM amorphous magnetic material machine. IEEE Trans. Ind. Electron. 2017, 65, 5376-5383. [CrossRef]

133. Cao, Z.; Mahmoudi, A.; Kahourzade, S.; Soong, W.L.; Summers, J.R. A Comparative Study of Axial-Flux versus Radial-Flux Induction Machines. In Proceedings of the 2020 IEEE International Conference on Power Electronics, Drives and Energy Systems (PEDES), Jaipur, India, 16-19 December 2020; pp. 1-6.

134. Mlot, A.; Łukaniszyn, M.; Korkosz, M. Magnet loss analysis for a high-speed PM machine with segmented PM and modified tooth-tips shape. Arch. Electr. Eng. 2016, 65, 671-683. [CrossRef]

135. Lim, J.-W.; Kim, Y.-J.; Jung, S.-Y. Numerical investigation on permanent-magnet eddy current loss and harmonic iron loss for pm skewed ipmsm. J. Magn. 2011, 16, 417-422. [CrossRef] 
136. Su, P.; Hua, W.; Hu, M.; Chen, Z.; Cheng, M.; Wang, W. Analysis of PM eddy current loss in rotor-PM and stator-PM flux-switching machines by air-gap field modulation theory. IEEE Trans. Ind. Electron. 2019, 67, 1824-1835. [CrossRef]

137. Rahideh, A.; Korakianitis, T. Analytical magnetic field distribution of slotless brushless permanent magnet motors-Part I. Armature reaction field, inductance and rotor eddy current loss calculations. IET Electr. Power Appl. 2012, 6, 628-638. [CrossRef]

138. Kanazawa, S.; Takahashi, N.; Kubo, T. Measurement and analysis of AC loss of NdFeB sintered magnet. Electr. Eng. Jpn. 2006, 154, 8-15. [CrossRef]

139. Yang, G.; Zhang, C. Computationally Efficient PM Power Loss Mapping for PWM Drive Surface-Mounted Permanent Magnet Synchronous Machines. Appl. Sci. 2021, 11, 3246. [CrossRef]

140. Burnand, G.; Araujo, D.M.; Koechli, C.; Perriard, Y. Validation by measurements of a windage losses model for very-high-speed machines. In Proceedings of the 2017 20th International Conference on Electrical Machines and Systems (ICEMS), Sydney, NSW, Australia, 11-14 August 2017; pp. 1-4. [CrossRef]

141. Wrobel, R.; Vainel, G.; Copeland, C.; Duda, T.; Staton, D.; Mellor, P.H. Investigation of mechanical loss components and heat transfer in an axial-flux PM machine. IEEE Trans. Ind. Appl. 2015, 51, 3000-3011. [CrossRef]

142. Roshandel, N.F.E.; Mahmoudi, A.; Kahourzade, S.; Tahir, A. Propulsion System of Electric Vehicles: Review. In Proceedings of the 2021 Australasian Universities Power Engineering Conference, Perth, WA, Australia, 26-30 September 2021.

143. Itoh, Y.; Sakai, K.; Makino, Y. In-wheel motor system. NTN Tech. Rev. 2011, 79, 22-28.

144. Fang, Y.; Ruan, J.; Walker, P.; Zhang, N. Comparison of effect on motor among 2-, 3-and 4-speed transmission in electric vehicle. In Proceedings of the 2017 IEEE International Conference on Mechatronics (ICM), Churchill, VIC, Australia, 13-15 February 2017; pp. $455-459$.

145. Höhn, B.-R.; Michaelis, K.; Hinterstoißer, M. Optimization of gearbox efficiency. Goriva Maz. 2009, 48, 462.

146. Lynwander, P. Gear Drive Systems: Design and Application; CRC Press: Boca Raton, FL, USA, 2019.

147. Biermann, J.-W. Measurement system for CV joint efficiency. SAE Trans. 1999, 108, 1724-1730.

148. Novo, F.M.F.; de Souza, M.M.; Savoy, J.; do Carmo Silva, M.A. Analysis of the Vibration Modes of an Automotive Propeller Shaft Using FEM and Analytical Models; 21st SAE Brasil International Congress and Exhibition, 2 October 2012; SAE Technical Paper; SAE International: Warrendale, PA, USA, 2012.

149. Foulard, S.; Rinderknecht, S.; Ichchou, M.; Perret-Liaudet, J. Automotive drivetrain model for transmission damage prediction. Mechatronics 2015, 30, 27-54. [CrossRef]

150. Ripard, V. Tribological Characterization of Greased Drive-Shaft: Evaluation of Constant Velocity Joint Durability; Université de Lyon: Lyon, France, 2019.

151. Cirelli, M.; Giannini, O.; Cera, M.; de Simoni, F.; Valentini, P.P.; Pennestrì, E. The mechanical efficiency of the Rzeppa transmission joint. Mech. Mach. Theory 2021, 164, 104418. [CrossRef]

152. Lohse-Busch, H.; Stutenberg, K.; Duoba, M.; Liu, X.; Elgowainy, A.; Wang, M.; Wallner, T.; Richard, B.; Christenson, M. Automotive fuel cell stack and system efficiency and fuel consumption based on vehicle testing on a chassis dynamometer at minus $18{ }^{\circ} \mathrm{C}$ to positive $35^{\circ} \mathrm{C}$ temperatures. Int. J. Hydrogen Energy 2020, 45, 861-872. [CrossRef]

153. Lei, Y.-L.; Jia, Y.-Z.; Fu, Y.; Liu, K.; Zhang, Y.; Liu, Z.-J. Car fuel economy simulation forecast method based on CVT efficiencies measured from bench test. Chin. J. Mech. Eng. 2018, 31, 83. [CrossRef]

154. Ruan, J.; Walker, P.D.; Wu, J.; Zhang, N.; Zhang, B. Development of continuously variable transmission and multi-speed dual-clutch transmission for pure electric vehicle. Adv. Mech. Eng. 2018, 10, 1687814018758223. [CrossRef]

155. Fu, B.; Zhou, Y.; Cao, C.; Li, Q.; Zhang, F. Research on Power Loss of Continuously Variable Transmission Based on Driving Cycles. In Proceedings of the IOP Conference Series: Earth and Environmental Science, Shanghai, China, 27-29 April 2018; Volume 108, p. 52054.

156. Jneid, M.S.; Harth, P.; Ficzere, P. In-wheel-motor electric vehicles AND their associated drivetrains. Int. J. Traffic Transp. Eng. 2020, $10,415-431$.

157. Nell, M.; Lenz, J.; Hameyer, K. Scaling laws for the FE solutions of induction machines. Arch. Electr. Eng. 2019, 68, 677-695.

158. Wan, Y.; Cui, S.; Wu, S.; Song, L. Electromagnetic design and losses analysis of a high-speed permanent magnet synchronous motor with toroidal windings for pulsed alternator. Energies 2018, 11, 562. [CrossRef]

159. Raminosoa, T.; Aytug, T. Impact of ultra-conducting winding on the power density and performance of non-heavy rare earth traction motors. In Proceedings of the 2019 IEEE International Electric Machines \& Drives Conference (IEMDC), San Diego, CA, USA, 12-15 May 2019; pp. 2107-2114. [CrossRef]

160. Axtmann, C.; Kolb, J.; Braum, M. Efficiency map computation of arbitrary converter topologies in EV powertrains. In Proceedings of the 2016 IEEE 2nd Annual Southern Power Electronics Conference (SPEC), Auckland, New Zealand, 5-8 December 2016; pp. 1-6. [CrossRef]

161. Kärkkäinen, H.; Aarniovuori, L.; Niemelä, M.; Pyrhönen, J. Converter-fed induction motor losses in different operating points. In Proceedings of the 2016 18th European Conference on Power Electronics and Applications (EPE'16 ECCE Europe), Karlsruhe, Germany, 5-9 September 2016; pp. 1-8.

162. Karkkainen, H.; Aarniovuori, L.; Niemela, M.; Pyrhonen, J. Converter-fed induction motor efficiency: Practical applicability of IEC methods. IEEE Ind. Electron. Mag. 2017, 11, 45-57. [CrossRef]

163. IEC/TS 60034-2-3. Rotating Electrical Machines_Part 2-3: Specific Test Methods for Determining Losses and Efficiency of Converter-Fed AC Induction Motors; International Electrotechnical Commission: London, UK, 2013; pp. 60032-60034. 
164. Boglietti, A.; Cavagnino, A.; Cossale, M.; Tenconi, A.; Vaschetto, S. Efficiency determination of converter-fed induction motors: Waiting for the IEC 60034-2-3 standard. In Proceedings of the 2013 IEEE Energy Conversion Congress and Exposition, Denver, CO, USA, 15-19 September 2013; pp. 230-237.

165. Slemon, G.R.; Liu, X. Core losses in permanent magnet motors. IEEE Trans. Magn. 1990, 26, 1653-1655. [CrossRef]

166. Yogal, N.; Lehrmann, C.; Henke, M. Magnetic loss measurement of surface-mounted permanent magnet synchronous machines used in explosive environments. J. Eng. 2019, 2019, 3760-3765. [CrossRef]

167. Haines, G.G. Integrated Motor System Estimation Using Efficiency Maps. Ph.D. Thesis, School of Electrical and Electronic Engineering, University of Adelaide, Adelaide, SA, Australia, 2020.

168. Loayza, Y.; Reinap, A.; Alakula, M. Performance and efficiency evaluation of FPGA controlled IPMSM under dynamic loading. In Proceedings of the 8th IEEE Symposium on Diagnostics for Electrical Machines, Power Electronics \& Drives, Bologna, Italy, 5-8 September 2011; pp. 550-555. [CrossRef] 